\title{
Immunocompromised patients with acute respiratory distress syndrome: secondary analysis of the LUNG SAFE database
}

\author{
Andrea Cortegiani ${ }^{1 *} \mathbb{D}$, Fabiana Madotto ${ }^{2}$, Cesare Gregoretti ${ }^{1}$, Giacomo Bellani ${ }^{3,4}$, John G. Laffey ${ }^{5,6,7}$, Tai Pham ${ }^{6,7}$, \\ Frank Van Haren ${ }^{8,9}$, Antonino Giarratano ${ }^{1}$, Massimo Antonelli ${ }^{10}$, Antonio Pesenti ${ }^{11,12}$, Giacomo Grasselli ${ }^{11}$, \\ LUNG SAFE Investigators and the ESICM Trials Group
}

\begin{abstract}
Background: The aim of this study was to describe data on epidemiology, ventilatory management, and outcome of acute respiratory distress syndrome (ARDS) in immunocompromised patients.

Methods: We performed a post hoc analysis on the cohort of immunocompromised patients enrolled in the Large Observational Study to Understand the Global Impact of Severe Acute Respiratory Failure (LUNG SAFE) study. The LUNG SAFE study was an international, prospective study including hypoxemic patients in 459 ICUs from 50 countries across 5 continents.

Results: Of 2813 patients with ARDS, 584 (20.8\%) were immunocompromised, 38.9\% of whom had an unspecified cause. Pneumonia, nonpulmonary sepsis, and noncardiogenic shock were their most common risk factors for ARDS. Hospital mortality was higher in immunocompromised than in immunocompetent patients ( $52.4 \%$ vs $36.2 \%$; $p<0.0001$ ), despite similar severity of ARDS. Decisions regarding limiting life-sustaining measures were significantly more frequent in immunocompromised patients ( $27.1 \%$ vs $18.6 \% ; p<0.0001)$. Use of noninvasive ventilation (NIV) as first-line treatment was higher in immunocompromised patients (20.9\% vs $15.9 \% ; p=0.0048$ ), and immunodeficiency remained independently associated with the use of NIV after adjustment for confounders. Forty-eight percent of the patients treated with NIV were intubated, and their mortality was not different from that of the patients invasively ventilated ab initio.
\end{abstract}

Conclusions: Immunosuppression is frequent in patients with ARDS, and infections are the main risk factors for ARDS in these immunocompromised patients. Their management differs from that of immunocompetent patients, particularly the greater use of NIV as first-line ventilation strategy. Compared with immunocompetent subjects, they have higher mortality regardless of ARDS severity as well as a higher frequency of limitation of life-sustaining measures. Nonetheless, nearly half of these patients survive to hospital discharge.

Trial registration: ClinicalTrials.gov, NCT02010073. Registered on 12 December 2013.

Keywords: Acute respiratory failure, ARDS, Immunocompromised patients, Mechanical ventilation, Noninvasive ventilation

\footnotetext{
* Correspondence: cortegiania@gmail.com

'Department of Biopathology and Medical Biotechnologies (DIBIMED),

Section of Anesthesia, Analgesia, Intensive Care and Emergency, Policlinico

Paolo Giaccone, University of Palermo, Via del vespro 129, 90127 Palermo,

Italy

Full list of author information is available at the end of the article
}

C The Author(s). 2018 Open Access This article is distributed under the terms of the Creative Commons Attribution 4.0 International License (http://creativecommons.org/licenses/by/4.0/), which permits unrestricted use, distribution, and reproduction in any medium, provided you give appropriate credit to the original author(s) and the source, provide a link to the Creative Commons license, and indicate if changes were made. The Creative Commons Public Domain Dedication waiver (http://creativecommons.org/publicdomain/zero/1.0/) applies to the data made available in this article, unless otherwise stated. 


\section{Background}

In recent decades, significant advances in the management of immunocompromised patients have led to improved survival rates [1-3]. Hence, intensive care unit (ICU) admission and invasive life-sustaining treatments are offered with increasing frequency to these patients $[3,4]$. However, several studies show that the prognosis of critically ill patients with active malignancies or immunodeficiency remains poor, especially when the cause of ICU admission is acute respiratory distress syndrome (ARDS) requiring invasive mechanical ventilation (IMV) [5-11]. Data about incidence, causes, management, and outcomes of ARDS in immunocompromised patients are scarce. The best ventilatory strategy in this population is still uncertain, and available literature data on the role of noninvasive ventilation (NIV) are conflicting [12-22]. Recently, researchers in the Large Observational Study to Understand the Global Impact of Severe Acute Respiratory Failure (LUNG SAFE study) investigated the incidence, management, and clinical outcomes in patients with acute hypoxemic respiratory failure (AHRF) requiring ventilatory support, with a specific focus on ARDS [23]. This aim of this post hoc subgroup analysis was to describe the epidemiology, clinical characteristics, ventilatory management (with particular attention to the use of NIV), and outcomes of ARDS in the subset of patients with clinically significant immunodeficiency.

\section{Methods}

\section{LUNG SAFE: patients, study design, and data collection}

LUNG-SAFE was an international, multicenter, prospective observational cohort study conducted in a 459 ICUs worldwide. During 4 consecutive weeks in the winter of 2014 (February-March 2014 in the Northern Hemisphere and June-August 2014 in the Southern Hemisphere), participating ICUs enrolled patients undergoing IMV or NIV. Participating ICUs obtained ethics committee approval and either patient consent or waiver of consent as per local guidelines. National coordinators, site investigators, and endorsing societies are listed in Additional file 1. Exclusion criteria were age $<16$ years or lack of informed consent when required. Patients were screened daily for AHRF, defined as follows: (1) ratio of partial pressure of arterial oxygen to fraction of inspired oxygen $\left(\mathrm{PaO}_{2} / \mathrm{FiO}_{2}\right) \leq 300 \mathrm{mmHg}$ while receiving IMV or NIV with positive end-expiratory pressure (PEEP) $\geq 5 \mathrm{cmH}_{2} \mathrm{O}$ and (2) new radiological pulmonary parenchymal abnormalities. In patients with AHRF, a more detailed set of data was collected to determine whether they met the Berlin definition criteria for ARDS. Data on comorbidities, etiology of AHRF, and risk factors for ARDS were recorded. Data on arterial blood gases, ventilatory support, use of adjunctive therapies (e.g., prone positioning, extracorporeal membrane oxygenation, neuromuscular blockade), severity of ARDS, and other organ involvement by modified nonpulmonary Sequential Organ Failure Assessment (SOFA) score [24] were collected on selected days. The following clinical endpoints were assessed: ICU and hospital survival, censored at 90 days after enrollment; duration of mechanical ventilation; changes in ARDS severity; and decision to withhold or withdraw life-sustaining therapies. A full description of the methods of the LUNG SAFE study, including the full study protocol, case report form (CRF), sample size, and quality control, can be found in the original study paper [23].

\section{Immunocompromised patient cohort and definitions}

We defined "immunocompromised" patients as all patients with at least one of the following conditions listed in the LUNG SAFE CRF: (1) immunosuppression (defined as viral immunosuppression, neoplastic disease, immunosuppressive drugs including steroids, chemotherapy, or congenital immunosuppression), (2) active hematologic malignancy (i.e., still requiring treatment), and (3) active neoplasm (i.e., a neoplasm that has not been resected, still requires treatment, or with metastasis). Patients without these conditions were classified as "controls." For the purposes of this analysis, the study population was restricted to the subset of patients fulfilling ARDS criteria on day 1 or 2 following the onset of AHRF.

In regard to management, patients were subdivided in three ventilation subgroups: (1) IMV, defined as patients invasively ventilated from day 1 , independently of the type of support received after the eventual extubation; (2) NIV, defined as patients treated exclusively with NIV from day 1 to study exit (i.e., ICU discharge or death); and (3) NIV failure, defined as patients initially treated with NIV and subsequently intubated during the study period. The term NIV encompassed all forms of NIV modes and interfaces (including continuous positive airway pressure). ARDS severity was assessed from the first to the second day from ARDS onset, according to the Berlin definition criteria: mild $\left(\mathrm{PaO}_{2} / \mathrm{FiO}_{2}\right.$ 201$300 \mathrm{mmHg})$, moderate $\left(\mathrm{PaO}_{2} / \mathrm{FiO}_{2} 101-200 \mathrm{mmHg}\right)$, and severe $\left(\mathrm{PaO}_{2} / \mathrm{FiO}_{2} \leq 100 \mathrm{mmHg}\right)$. Changes in ARDS severity were evaluated in patients staying in the ICU for at least 2 days, and they were classified into four categories: (1) no change, (2) worsening (shift to a more severe category), (3) improvement (shift to a less severe category), and (4) resolution. Duration of invasive ventilation was computed as the number of days that the patient required IMV up to day 28. Survival was evaluated at ICU and hospital discharge or at day 90, whichever event occurred first.

\section{Statistical analysis}

Continuous variables were expressed as mean (SD) or median (IQR), and categorical variables were presented 
as count and percent. No assumptions were made for missing data, which were rare [23]. To assess differences between groups, we used Student's $t$ test or the Wilcoxon rank-sum test (according normality distribution of data) for continuous variables and the $x^{2}$ or Fisher's exact test (according sample size) for proportions. We used analysis of variance or the Kruskal-Wallis test (as appropriate) and the $X^{2}$ test (or Fisher's exact test) to assess differences among the NIV, NIV failure, and IMV groups. The Bonferroni correction was applied to determine significance in the setting of multiple comparisons.

To evaluate factors associated with the use of NIV, we applied a multivariable logistic regression model, and the independent predictors (demographic characteristics, comorbidities, ARDS risk factors, and clinical parameters concerning the illness severity of ARDS onset) were identified through a stepwise regression approach. This approach combines forward and backward selection methods (combined with a significance level of 0.05 for both entry and retention) in an iterative procedure to select predictors in the final multivariable model. This approach was also applied to identify factors associated with hospital mortality in immunocompromised patients. In this case, the stepwise approach also evaluated as possible predictors ventilator setting variables measured at ARDS onset.

Survival analysis was performed according to the Kaplan-Meier method. We assumed that patients discharged alive from the hospital before 90 days were alive on day 90 . The log-rank test was used to compare survival curves among groups.

All $p$ values were two-sided, and values less than 0.05 were considered significant. Statistical analyses were carried out with $\mathrm{R}$ version 3.3.3 ( $\mathrm{R}$ Project for Statistical Computing; https://www.r-project.org/) and SAS version 9.4 software (SAS Institute, Cary, NC, USA).

\section{Results}

\section{Baseline patient characteristics}

A total of 459 ICUs from 50 countries enrolled patients in the LUNG SAFE study. Among 12,906 mechanically ventilated patients, 4499 had AHRF, and of these, 2813 fulfilled the Berlin criteria for ARDS on day 1 or 2 . Among ARDS patients, 584 (20.8\%) were immunocompromised (Fig. 1). Of these, 232 (39.7\%) had an active neoplasm and 138 (23.6\%) had a hematologic malignancy, whereas the causes of immunosuppression were not specified in $38.7 \%$. Table 1 shows baseline characteristics of immunocompromised and control patients. Immunocompromised subjects were younger than controls (60.3 vs 61.6 years; $p=0.0163$ ) and had a lower body mass index (BMI) $\left(25.5 \pm 5.8\right.$ vs $\left.28.1 \pm 9.2 \mathrm{~kg} / \mathrm{m}^{2} ; p<0.0001\right)$. They had a lower prevalence of chronic obstructive pulmonary disease, diabetes mellitus, and heart failure

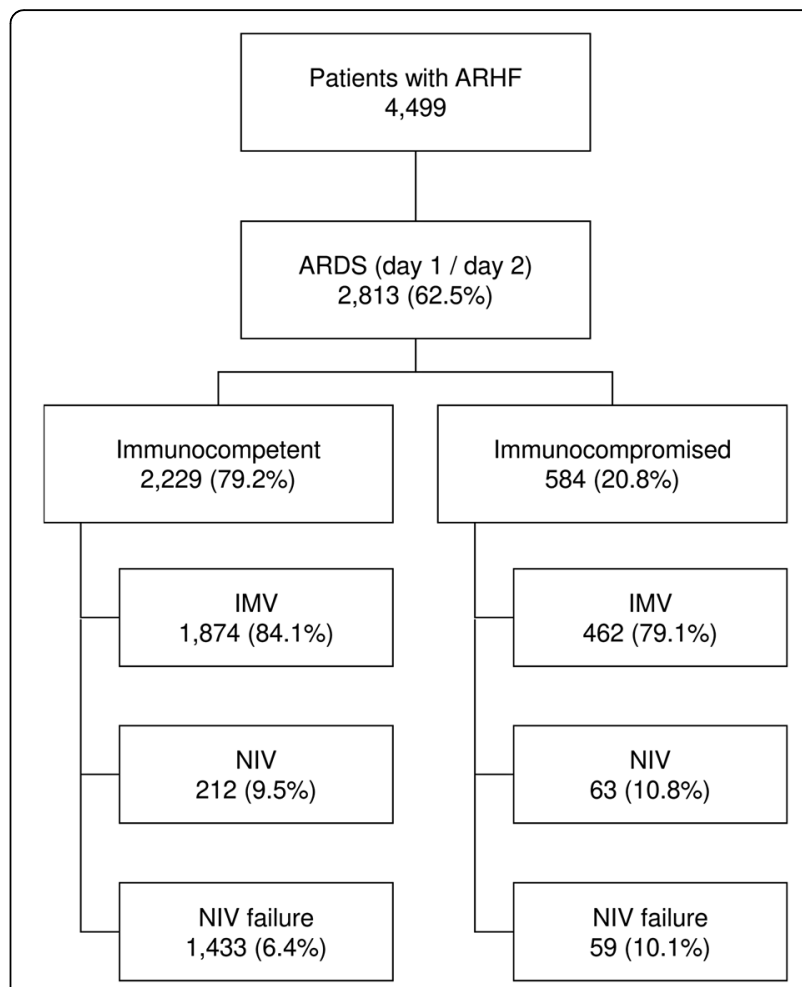

Fig. 1 Flow diagram of the study. Flow diagram showing the distribution of patients included in this analysis dataset, according to ventilation subgroup. AHRF acute hypoxemic respiratory failure, ARDS Acute respiratory distress syndrome, IMV Patients invasively ventilated from day 1 , independently of the type of support received after the eventual extubation, NIV Patients treated exclusively with noninvasive ventilation, from day 1 to study exit, independently of outcome, NIV failure Patients initially treated with noninvasive ventilation and subsequently intubated during the study period

(New York Heart Association classes III-IV) and a higher incidence of pneumonia, pulmonary vasculitis, and noncardiogenic shock. Among immunocompromised patients, $28.6 \%$ had mild, $46.4 \%$ moderate, and $25.0 \%$ severe ARDS, and the most common risk factors for ARDS were pneumonia (70.5\%), nonpulmonary sepsis (16.1\%), and noncardiogenic shock (10.3\%). Nonpulmonary SOFA score at day 1 and ARDS severity were similar between immunocompromised and controls. Additional file $2 \mathrm{com}$ pares comorbidities, ARDS severity, and nonpulmonary SOFA score in the three ventilation subgroups (IMV, NIV, and NIV failure) among immunocompromised patients. Mean patient age in the NIV subgroup was older than in the other two subgroups, and the difference between NIV and IMV was statistically significant (65.2 vs 59.7 years; $p=0.0045)$. Comorbidities and $\mathrm{PaO}_{2} / \mathrm{FiO}_{2}$ were not different among the subgroups. There was a marked difference in the mean nonpulmonary SOFA score, which was significantly higher in IMV than in NIV $(7.0 \pm 3.9$ vs $3.7 \pm 3.1$; $p<0.0001)$ and NIV failure subgroups $(7.0 \pm 3.9$ vs $5.3 \pm 3.6 ; p=0.0023$ ). 
Table 1 Patients characteristics in immunocompetent (Control) and immunocompromised (Study) groups

\begin{tabular}{|c|c|c|c|}
\hline Patients characteristics & $\begin{array}{l}\text { Control } \\
(n=2229)\end{array}$ & $\begin{array}{l}\text { Study } \\
(n=584)\end{array}$ & $p$ Value \\
\hline \multicolumn{4}{|l|}{ Sex, age, and $\mathrm{BMI}$} \\
\hline Women, $n(\%)$ & $837(37.6)$ & $247(42.3)$ & 0.0360 \\
\hline Age, yr, mean $\pm S D$ & $61.6 \pm 17.1$ & $60.3 \pm 15.5$ & 0.0163 \\
\hline $\mathrm{BMI}\left(\mathrm{kg} / \mathrm{m}^{2}\right)$, mean $\pm \mathrm{SD}$ & $28.1 \pm 9.2$ & $25.5 \pm 5.8$ & $<0.0001$ \\
\hline \multicolumn{4}{|l|}{ Comorbidities, $n$ (\%) } \\
\hline COPD & $522(23.4)$ & $85(14.6)$ & $<0.0001$ \\
\hline Diabetes mellitus & $523(23.5)$ & $90(15.4)$ & $<0.0001$ \\
\hline Hearth failure (NYHA classes III-IV) & $260(11.7)$ & $30(5.1)$ & $<0.0001$ \\
\hline Chronic renal failure & $222(10.0)$ & $64(11.0)$ & 0.4769 \\
\hline Chronic liver failure (Child-Pugh class C) & $91(4.1)$ & $21(3.6)$ & 0.5924 \\
\hline Home ventilation & $52(2.3)$ & $7(1.2)$ & 0.0886 \\
\hline \multicolumn{4}{|l|}{ ARDS risk factors, $n(\%)$} \\
\hline Pneumonia & $1271(57.0)$ & $412(70.5)$ & $<0.0001$ \\
\hline Pulmonary contusion & $86(3.9)$ & $1(0.2)$ & $<0.0001$ \\
\hline Pulmonary vasculitis & $7(0.3)$ & $7(1.2)$ & 0.0140 \\
\hline Major trauma & $111(5.0)$ & $1(0.2)$ & $<0.0001$ \\
\hline Aspiration of gastric contents & $348(15.6)$ & $54(9.2)$ & $<0.0001$ \\
\hline Pancreatitis & $54(2.4)$ & $5(0.9)$ & 0.0187 \\
\hline Noncardiogenic shock & $154(6.9)$ & $60(10.3)$ & 0.0063 \\
\hline Drug overdose & $46(2.1)$ & $5(0.9)$ & 0.0515 \\
\hline Severe burns & $8(0.4)$ & $0(0.0)$ & 0.2183 \\
\hline Inhalational injury & $58(2.6)$ & $12(2.1)$ & 0.4498 \\
\hline Drowning & $1(0.04)$ & $1(0.2)$ & 0.3722 \\
\hline Nonpulmonary sepsis & $361(16.2)$ & $94(16.1)$ & 0.9535 \\
\hline Blood transfusions & $82(3.7)$ & $29(5.0)$ & 0.1550 \\
\hline Other risk factors & $61(2.7)$ & $12(2.2)$ & 0.4925 \\
\hline None & $194(8.7)$ & $40(6.8)$ & 0.1487 \\
\hline \multicolumn{4}{|l|}{ Cause of immunosuppression, $n(\%)$} \\
\hline Known (hematologic and/or active neoplasm) & - & $357(61.1)$ & - \\
\hline Unknown & - & $227(38.9)$ & - \\
\hline \multicolumn{4}{|l|}{ Illness severity at ARDS onset } \\
\hline \multicolumn{4}{|l|}{ Nonpulmonary SOFA score ${ }^{a}$, mean \pm SD } \\
\hline First day of ARDS & $6.2 \pm 4.1$ & $6.5 \pm 4.0$ & 0.1150 \\
\hline Second day of ARDS & $6.3 \pm 4.3$ & $6.7 \pm 4.3$ & 0.0283 \\
\hline $\mathrm{PaO}_{2} / \mathrm{FiO}_{2}$ ratio, $\mathrm{mmHg}$, mean $\pm \mathrm{SD}$ & $161.3 \pm 67.1$ & $157.2 \pm 67.9$ & 0.1660 \\
\hline Mild ARDS $^{b}, n(\%)$ & $666(29.9)$ & $167(28.6)$ & 0.5455 \\
\hline Moderate ARDS ${ }^{\mathrm{b}}, n(\%)$ & $1067(47.9)$ & $271(46.4)$ & 0.5280 \\
\hline Severe ARDS ${ }^{\mathrm{b}}, n(\%)$ & 496 (22.3) & $146(25.0)$ & 0.1590 \\
\hline
\end{tabular}

Abbreviations: BMI Body mass index, ARDS Acute respiratory distress syndrome, COPD Chronic obstructive pulmonary disease, NYHA New York Heart Association, SOFA Sequential Organ Failure Assessment, $\mathrm{PaO}_{2} / \mathrm{FiO}_{2}$ Ratio of partial pressure of arterial oxygen to fraction of inspired oxygen

Note: Bold $p$ values represent a statistically significant difference between the two groups

${ }^{a}$ Nonpulmonary SOFA score adjusted for missing values

bSeverity of ARDS was evaluated according to the Berlin definition 
Type of ventilatory support, ventilator setting, and adjunctive measure/therapies

Figure 1 summarizes the type of ventilatory support in enrolled patients. On day 1 of ARDS, IMV was the most frequent type of ventilatory approach in both groups; however, NIV use as first-line treatment was significantly more frequent in immunocompromised than in immunocompetent patients $(20.9 \%$ vs $15.9 \% ; p=0.0044)$. The proportion of patients remaining on NIV from day 1 to study exit (NIV subgroup) was similar, whereas the incidence of NIV failure was significantly higher in immunocompromised patients $(10.1 \%$ vs $6.4 \% ; p=0.0021)$.

A multivariable logistic regression model revealed that, adjusting on confounders, immunodeficiency was independently associated with the use of NIV (OR, 1.567; 95\% CI, $1.217-2.017 ; p=0.0005)$. Other factors associated with NIV are shown in Additional file 3.

Additional file 4 compares the ventilator settings on the first day of ARDS between immunocompromised and control patients: $\mathrm{FiO}_{2}$ and respiratory rate and PEEP were statistically significantly higher in immunocompromised patients, but the difference for PEEP was not clinically relevant. There was no difference in tidal volume, peak and plateau pressures, and the proportion of patients with spontaneous ventilation. No significant differences were observed in adjunctive therapies, except for a significantly higher use of continuous neuromuscular blocking agents in the immunocompromised group (22.6\% vs $18.5 \% ; p=0.0266$ ) (Additional file 5). Additional file 6 describes ventilator settings in immunocompromised and immunocompetent (control) patients, stratified by the type of ventilator support (IMV, NIV, NIV failure).

\section{Clinical endpoints}

Table 2 compares selected clinical endpoints in immunocompromised and control patients. Hospital mortality and ICU mortality were significantly higher in immunocompromised subjects (respectively, $52.4 \%$ vs $36.2 \%, \quad p<0.0001$; and $45.5 \%$ vs $31.3, p<0.0001$ ), whereas there was no difference in duration of mechanical ventilation and changes in ARDS severity. Survival curves for hospital (or 90-day) mortality are shown in Fig. 2. The decision to withhold and/or withdraw life-sustaining measures was significantly more frequent in immunocompromised patients (Table 2). The same clinical endpoints were also analyzed in the cohort of

Table 2 Clinical endpoints in immunocompetent (Control) and immunocompromised (Study) patients

\begin{tabular}{|c|c|c|c|}
\hline Clinical endpoints & $\begin{array}{l}\text { Control } \\
(n=2229)\end{array}$ & $\begin{array}{l}\text { Study } \\
(n=584)\end{array}$ & $p$ Value \\
\hline IMV during ICU stay, $n$ (\%) & $1874(84.1)$ & $462(79.1)$ & 0.0044 \\
\hline NIV success during ICU stay, $n$ (\%) & $212(9.5)$ & $63(10.8)$ & 0.3551 \\
\hline NIV failure during ICU stay, $n$ (\%) & $143(6.4)$ & $59(10.1)$ & 0.0021 \\
\hline Duration of mechanical ventilation, $d$, median $\left(Q_{1}-Q_{3}\right)$ & $8.0(4.0-15.0)$ & $8.0(4.0-14.0)$ & 0.4213 \\
\hline Progression/regression of ARDS,$n(\%)$ & & & 0.5613 \\
\hline No change & $824(41.7)$ & $201(39.6)$ & \\
\hline Progression & $214(10.8)$ & $55(10.8)$ & \\
\hline Regression & $422(21.3)$ & $123(24.2)$ & \\
\hline Resolution & $518(26.2)$ & $129(25.4)$ & \\
\hline \multicolumn{4}{|l|}{ Limitation of life-sustaining measures, $n(\%)$} \\
\hline Decision to withhold life-sustaining measures & $415(18.6)$ & $158(27.1)$ & $<0.0001$ \\
\hline Decision to withdraw life-sustaining measures & $356(16.0)$ & $129(22.1)$ & 0.0005 \\
\hline Decision to withhold or withdraw life-sustaining measures & $507(22.7)$ & $195(33.4)$ & $<0.0001$ \\
\hline ICU mortality ${ }^{\mathrm{b}}, n(\%)$ & $698(31.3)$ & $266(45.5)$ & $<0.0001$ \\
\hline \multicolumn{4}{|l|}{ Hospital mortality ${ }^{c}, n(\%)$} \\
\hline All patients & $804(36.2)$ & $304(52.4)$ & $<0.0001$ \\
\hline Patients with limitations of life-sustaining measures ${ }^{d}$ & $419(82.6)$ & $173(88.7)$ & 0.0473 \\
\hline
\end{tabular}

Abbreviations: ARDS Acute respiratory distress syndrome, IMV Invasive mechanical ventilation, ICU Intensive care unit, NIV Noninvasive mechanical ventilation, $Q_{1}$ First quartile, $Q_{3}$ Third quartile

${ }^{a}$ Change in ARDS severity (according Berlin definition) was not evaluable for 327 pients (251 immunocompetent and 76 immunocompromised patients)

${ }^{b}$ Mortality is defined as mortality at ICU discharge or at the 90th day in the ICU after onset of acute hypoxemic respiratory failure, whichever event occurred first ${ }^{c}$ Mortality is defined as mortality at hospital discharge or at the 90th day in the hospital after onset of acute hypoxemic respiratory failure, whichever event occurred first

${ }^{\mathrm{d}}$ Mortality assessed on patients with a decision to withhold or withdraw life-sustaining measures

Note: Bold $p$ values represent a statistically significant difference between the two groups 


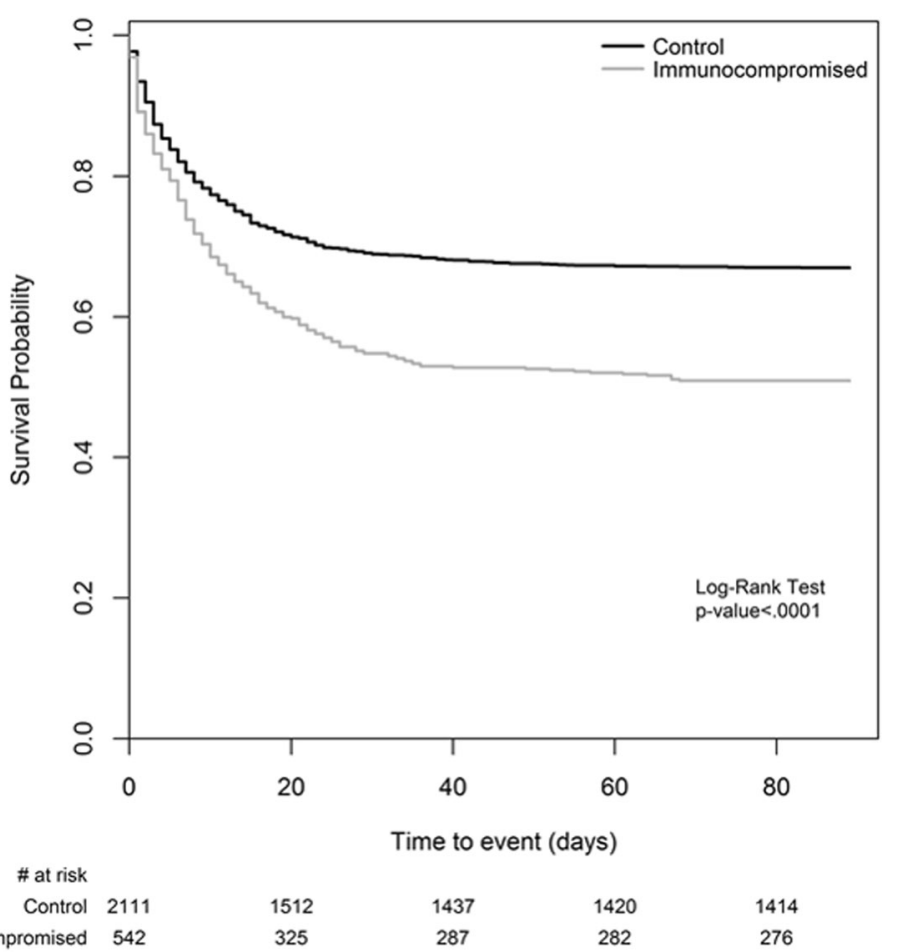

Fig. 2 Kaplan-Meier curve for hospital survival. Mortality was defined as mortality at hospital discharge or at 90 days after onset of acute hypoxemic respiratory failure, whichever event occurred first. We assumed that patients discharged alive from the hospital before 90 days were alive on day 90. Note: The number of patients at risk reported at the bottom of the figure is referred to as the end of the corresponding day

immunocompromised patients according to the ventilation subgroup (Table 3). Duration of mechanical ventilation and decisions of limitation (both withholding and withdrawal) of life-sustaining measures were not different among the subgroups. ICU mortality was significantly lower in NIV patients than in the IMV (28.6\% vs $46.3 \% ; p=0.0078)$ and NIV failure $(28.6 \%$ vs $57.6 \%$; $p=0.0012$ ) subgroups. Of the NIV patients who died, $68 \%$ had a limitation of life-sustaining measures. The incidence of NIV failure was $48 \%$. ICU and hospital mortality of patients with NIV failure were significantly higher than those of patients managed exclusively with NIV (respectively, $57.6 \%$ vs $28.6 \%, p=0.012$; and 62.7 vs $39.7 \%, p=0.011$ ), whereas they did not differ from those of IMV patients. Survival curves for hospital (or 90-day) mortality of immunocompromised patients stratified by ARDS severity and by ventilation subgroups are shown in Additional files 7 and 8 , respectively. In a multivariable logistic regression model, factors independently associated with hospital mortality in immunocompromised patients were higher nonpulmonary SOFA score (OR, 1.079; 95\% CI, 1.026-1.134; $p=0.0032$ ), higher peak inspiratory pressure level (OR, 1.028; 95\% CI, 1.007-1.051; $p=0.0097$ ), lower $\mathrm{PaO}_{2} /$ $\mathrm{FiO}_{2}$ ratio (OR, 0.995; 95\% CI, 0.992-0.998; $p=0.0022$ ), lower degree of improvement in $\mathrm{PaO}_{2} / \mathrm{FiO}_{2}$ ratio between day 1 and day 2 of ARDS (OR, 0.996; 95\% CI, 0.993-0.999; $p=0.0058$ ), and lower BMI (OR, 0.944; 95\% CI, 0.91-0.98; $p=0.0023$ ) (Additional file 9). According to the investigators' clinical judgment, in immunocompromised patients, the most common main factor leading to death in ICU was respiratory failure $(51.5 \%)$, followed by cardiovascular failure. In contrast, cardiovascular failure was the most common factor in the control group (Additional file 10).

Additional file 11 describes patient characteristics and clinical endpoints in immunocompetent (control) patients according to type of ventilator support. Because the lack of a precise definition of the cause of immunosuppression in a relevant proportion of patients may affect the strength of our findings, we compared baseline patient characteristics and clinical outcomes in patients with a "known" cause of immunosuppression (i.e., those with active hematologic malignancy or active neoplasm) and in patients with an unspecified ("unknown") cause of immunosuppression (i.e., those indicated in the CRF with the generic term immunosuppression). The results of this analysis are reported in Additional file 12. Briefly, patients with an unspecified cause of immunosuppression were significantly younger ( $55.7 \pm 15.6$ vs $63.1 \pm 14.8$ years; $p<0.0001)$ and had lower hospital mortality $(41.6 \%$ vs 59.3\%; $p<0.0001)$ and fewer limitations of life-sustaining measures $(27.3 \%$ vs $37.3 \% ; p=0.013)$. 
Table 3 Clinical endpoints in immunocompromised (Study) patients according to ventilation subgroup

\begin{tabular}{|c|c|c|c|c|}
\hline Clinical endpoints & $\begin{array}{l}\text { IMV } \\
(n=462)\end{array}$ & $\begin{array}{l}\text { NIV } \\
(n=63)\end{array}$ & $\begin{array}{l}\text { NIV failure } \\
(n=59)\end{array}$ & $p$ Value \\
\hline Duration of mechanical ventilation, $d$, median $\left(Q_{1}-Q_{3}\right)$ & $8.0(4.0-14.0)$ & - & $8.0(5.0-15.0)$ & 0.4352 \\
\hline \multicolumn{5}{|l|}{ Progression/regression of $\mathrm{ARDS}^{\mathrm{a}}, n(\%)$} \\
\hline No change & $161(40.1)$ & $18(32.1)$ & $22(43.1)$ & 0.4449 \\
\hline Progression & $43(10.7)$ & $5(8.9)$ & $7(13.7)$ & 0.7199 \\
\hline Regression & $103(25.7)$ & $4(7.1)^{b}$ & $16(31.4)^{c}$ & 0.0045 \\
\hline Resolution & $94(23.44)$ & $29(51.8)^{\mathrm{b}}$ & $6(11.8)^{c}$ & $<0.0001$ \\
\hline \multicolumn{5}{|l|}{ Limitation of life-sustaining measures, $n(\%)$} \\
\hline Decision to withhold life-sustaining measures & $124(26.8)$ & $18(28.6)$ & $16(27.1)$ & 0.9587 \\
\hline Decision to withdraw life-sustaining measures & $101(21.9)$ & $14(22.2)$ & $14(23.7)$ & 0.9480 \\
\hline Decision to withhold or withdraw life-sustaining measures & $154(33.3)$ & $21(33.3)$ & $20(33.9)$ & 0.9962 \\
\hline Before IMV or NIV start & $1(0.6)$ & $0(0.0)$ & $1(5.0)$ & 0.2062 \\
\hline ICU mortality ${ }^{\mathrm{d}}, n(\%)$ & $214(46.3)$ & $18(28.6)^{b}$ & $34(57.6)^{c}$ & 0.0043 \\
\hline \multicolumn{5}{|l|}{ Hospital mortality ${ }^{\mathrm{e}}, n(\%)$} \\
\hline All patients & $242(52.8)$ & $25(39.7)$ & $37(62.7)^{c}$ & 0.0362 \\
\hline Patients with limitations of life-sustaining measures ${ }^{f}$ & $137(89.0)$ & $17(81.0)$ & $19(95.0)$ & 0.3803 \\
\hline
\end{tabular}

Abbreviations: ARDS Acute respiratory distress syndrome, IMV Patients invasively ventilated from day 1 , independently of the type of support received after the eventual extubation, NIV Patients treated exclusively with noninvasive ventilation, from day 1 to study exit, independently of outcome, NIV failure Patients initially treated with noninvasive ventilation and subsequently intubated during the study period, $Q_{1}$ First quartile, $Q_{3}$ Third quartile

${ }^{a}$ Change in ARDS severity (according Berlin definition) was not evaluable for 76 immunocompromised patients (61 IMV, 7 NIV, and 8 NIV failure)

${ }^{\mathrm{b}}$ Statistically significant different from the IMV group

'Statistically significant different from the NIV group

${ }^{\mathrm{d}}$ Mortality is defined as mortality at ICU discharge or at the 90th day in ICU after onset of acute hypoxemic respiratory failure, whichever event occurred first

e Mortality is defined as mortality at hospital discharge or at the 90th day in hospital, after onset of acute hypoxemic respiratory failure, whichever event occurred first

${ }^{\mathrm{f}}$ Mortality assessed in patients with a decision to withhold or withdraw life-sustaining measures

Note: Bold $p$ values represent a statistically significant difference among the three groups

\section{Discussion}

The main findings of this analysis can be summarized as follows: immunosuppression is frequent in ARDS patients; causes of ARDS in immunocompromised patients are mainly related to infection; immunocompromised patients are more likely to receive NIV as first-line ventilatory treatment; and the outcome of ARDS is worse and limitation of life-sustaining measures is more frequent in immunocompromised patients. Among the 2813 ARDS patients included in the LUNG SAFE study, one-fifth were immunocompromised, and $62.7 \%$ of them had an active malignancy. In line with recent literature $[18,21]$, a diagnosis of active malignancy is considered as a cause of immunosuppression, owing to the negative effects on immune function of anticancer treatments and of the malignancy itself. All other causes of immune deficiency were identified by the generic variable "immunosuppression." To the best of our knowledge, this was the first prospective, multicenter study conducted on a large cohort of immunocompromised patients with a diagnosis of ARDS according to Berlin definition criteria [25], whereas previous studies relied on the definition of the American-European Consensus Conference on ARDS [26]. As expected, ARDS in immunocompromised patients was associated mainly with an infectious cause. Pneumonia, noncardiogenic shock, and pulmonary vasculitis were significantly more frequent in immunocompromised patients, whereas other risk factors for ARDS were more frequently represented in the control group.

Immunocompromised subjects had a significantly higher ICU and hospital mortality, despite similar ARDS severity and nonpulmonary SOFA score. Another subanalysis of the same database confirmed that active neoplasm, hematologic malignancies, and immunosuppression are independently associated with increased mortality [27]. In addition, the higher frequency of limitation of life-sustaining measures (probably as a result of perceived futility) may have contributed to the increased mortality of immunocompromised patients [27]. This is in line with the results of Laffey et al., who found that immunosuppression and cancer were among the factors associated with increased likelihood of limitation of life-sustaining therapies [27].

Hospital mortality of our patients was lower than that (64\%) reported by Azoulay et al. in a large retrospective analysis of 1004 patients with cancer and ARDS admitted to the ICU over a period of 21 years [28]. In that study, mortality did drop from $89 \%$ in the $1990-1995$ period to $52 \%$ in the $2006-2011$ period, matching the mortality rate of our population. 
The actual advantage of ICU admission of immunocompromised patients remains debated $[3,4,10,29,30]$. Our results demonstrate that almost $50 \%$ of immunocompromised patients with ARDS survive to hospital discharge, and this may support the decision to offer them at least an "ICU trial" [31]. Interestingly, our data show that once immunocompromised patients are intubated and invasively ventilated, they are managed very similarly to the general ARDS population with regard to ventilator settings and use of adjunctive therapies. As an example, the use of advanced "rescue" treatments (such as prone positioning and even extracorporeal membrane oxygenation) was similar between immunocompromised and control patients.

Two important questions on the optimal ventilatory management of AHRF in immunocompromised patients remain unanswered. First, is NIV the optimal first-line ventilatory support? Two randomized controlled trials conducted almost 20 years ago showed that NIV, compared with standard oxygen therapy, significantly reduces the rate of intubation and mortality [16, 17], but these findings have not been confirmed in more recent studies. A recent randomized trial on 374 immunocompromised patients with AHRF did not find any benefit of NIV over standard oxygen therapy [18]. Similarly, a post hoc analysis on immunocompromised patients enrolled in a large randomized trial comparing different noninvasive oxygenation strategies showed that first-line NIV was associated with the highest risk of intubation and mortality compared with standard oxygen and high-flow nasal cannula (HFNC) oxygen [21]. In our study, 20.9\% of immunocompromised patients received NIV as first-line ventilatory approach compared with $15.9 \%$ of controls, and the multivariable analysis revealed that immunodeficiency was independently associated with the use of NIV. This frequency of use of NIV equals exactly that reported by Gristina in a large population of patients with hematologic malignancies admitted to ICU in the years 2002-2006 [26]. In Azoulay's study, the global rate of NIV application was $38.6 \%$, but it decreased over the years, dropping to $26 \%$ in the period 2006-2011 [28]. In our study, patients treated exclusively with NIV had significantly lower mortality than patients requiring invasive ventilation. Of note, the majority of NIV patients who died had a decision of limitation of life-sustaining measures. Importantly, whereas ARDS severity was not different among ventilation subgroups, NIV patients had a markedly lower nonpulmonary SOFA score (Additional file 2: Table S1), indicating that patients with more severe organ failures were more frequently treated with invasive ventilatory support. However, the multivariable regression analysis did not identify the need for invasive ventilation as an independent predictor of death. This represents a major difference with Azoulay's study, where IMV (especially after failure of NIV) was a strong predictor of poor outcome [28]. Again, this can be explained at least in part by considering that Azoulay's study included patients from the year 1990, when the techniques of mechanical ventilation were completely different and protective ventilation was certainly not the standard of care.

The impact of NIV failure on patients' outcomes is the second important issue. We observed a significantly higher incidence of NIV failure in immunocompromised patients than in controls, in keeping with the observation of Thille that a diagnosis of active cancer is independently associated with NIV failure [32]. In our study, in $48 \%$ of immunocompromised patients initially treated with NIV, NIV failed, and they had a significantly worse mortality than patients successfully managed with NIV, as previously reported by Bellani et al. [23]. Less expected was the finding that mortality of NIV failure patients was not different from that of the patients managed $a b$ initio with IMV. However, two factors may limit the relevance of this observation: the relatively low number of patients in the NIV failure subgroup and the lack of information on the actual duration (i.e., in hours rather than days) of the NIV period before intubation, which would be important to know in the light of literature data showing that delaying endotracheal intubation after a prolonged NIV trial may negatively impact patient survival $[19,20]$. In line with our data, Demoule et al. recently observed a progressive reduction of the impact of NIV failure on mortality in a large population of AHRF patients also including immunocompromised subjects [33]. Taken together, these data probably suggest that better patient selection, earlier recognition of failure, and improvement in ventilation techniques may have contributed to limit the impact of NIV failure on mortality in recent years.

\section{Limitations}

The present study has several limitations. First, it is a post hoc analysis of a prospective multicenter observational trial, and unknown confounders associated with the subgroup analysis may bias the results. Although the data were prospectively collected from a high number of centers from 50 countries, different approaches to clinical decisions from different centers (e.g., decisions on withholding or withdrawing of life-sustaining measures) may have influenced the outcomes. Second, the criteria used to define the immunocompromised cohort were quite heterogeneous. It was impossible to stratify the patients according to the prognosis of baseline disease and to the severity of immune deficiency. Indeed, causes of immunosuppression, other than malignancies, were not specified in nearly $40 \%$ of the whole cohort of immunocompromised patients. Moreover, in patients with cancer, no information was available on the type of cancer, 
its staging, and the nature and timing of anticancer treatments. This lack of information, related to the LUNG SAFE original CRF, should be considered a major limitation because the outcome of immunocompromised patients is strictly dependent on the type of underlying diseases and associated therapeutic approach. All these factors may limit the generalizability of our findings. Third, to limit the burden on investigators, data were collected once daily only, and information on the actual hours of duration of ventilatory treatments was not available. This is particularly relevant for patients treated with NIV because the precise duration of NIV before the eventual intubation might be important to understand the impact of NIV failure on outcome [24]. Fourth, no information were provided on the type of interface used for NIV, a factor that can affect the outcome of NIV [34]. Moreover, patients treated with HFNC oxygen therapy were excluded from the LUNG SAFE study because they did not fulfill criteria for ARDS. Fifth, the LUNG SAFE study was conducted in a very large number of ICUs with different experience in the treatment of ARDS. This may be particularly relevant for immunocompromised patients, who may have better outcomes if treated in highly experienced, dedicated units [35].

\section{Conclusions}

Immunocompromised patients represent an important proportion of ARDS patients in the ICU. Compared with immunocompetent subjects, they had higher mortality, regardless of ARDS severity, and a higher frequency of limitation of life-sustaining measures. Nonetheless, nearly half of these patients survive to hospital discharge. They were more likely to receive NIV as the first ventilator strategy, and those who did not require invasive ventilation had a lower mortality. Mortality of immunocompromised patients who failed NIV was not different from that of patients treated $a b$ initio with IMV. These data should be considered in light of the nonspecific criteria used to define the immunocompromised population and the potentially heterogeneous approaches to clinical decision making in the participating centers.

\section{Additional files}

Additional file 1: List of LUNG SAFE investigators. Names and affiliations of the LUNG SAFE investigators. (PDF $172 \mathrm{~kb}$ )

Additional file 2: Table S1. Patient characteristics of immunocompromised patients according to the type of ventilator support. This table shows patient characteristics, including comorbidities, ARDS risk factors, and illness severity at ARDS onset of immunocompromised patients according to the type of ventilator support. (PDF $74 \mathrm{~kb}$ )

Additional file 3: Table S2. Factors associated with the use of noninvasive ventilation. Multivariate logistic regression model describing the factors associated with the use of noninvasive ventilation. (PDF $49 \mathrm{~kb}$ )
Additional file 4: Table S3. Ventilator settings during the first day of ARDS in the immunocompetent (Control) and immunocompromised (Study) groups. This table shows ventilator settings during the first day of ARDS in the immunocompetent (Control) and immunocompromised (Study) groups. (PDF $50 \mathrm{~kb}$ )

Additional file 5: Table S4. Adjunctive measures/therapies during at least one day during follow-up in immunocompetent and immunocompromised patients. This table shows the proportions of adjunctive measures/therapies during at least one day during follow-up in immunocompetent and immunocompromised patients. (PDF $97 \mathrm{~kb}$ )

Additional file 6: Table S6. Ventilator settings during the first day of ARDS in immunocompetent (Control) and immunocompromised (Study) patients, stratified by the type of ventilatory support (IMV, NIV, NIV failure). (PDF $60 \mathrm{~kb}$ )

Additional file 7: Figure S1. Kaplan-Meier curve for hospital survival in immunocompromised patients according to ARDS severity. Kaplan-Meier curve for hospital survival in immunocompromised patients according to ARDS severity. Mortality is defined as mortality at hospital discharge or at 90 days after onset of acute hypoxemic respiratory failure, whichever event occurred first. We assumed that patients discharged alive from the hospital before 90 days were alive on day 90 . Severity of ARDS was evaluated at the day of onset according to the Berlin definition. Note: The number of patients reported in the bottom of figure is referred to as the end of the corresponding day. (PDF $402 \mathrm{~kb}$ )

Additional file 8: Figure S2. This figure shows a Kaplan-Meier curve for hospital survival of immunocompromised patients according to the ventilation subgroup. This figure shows a Kaplan-Meier curve for hospital survival of immunocompromised patients according to the ventilation subgroup. Mortality is defined as mortality at hospital discharge or at 90 days after onset of acute hypoxemic respiratory failure, whichever event occurred first. We assumed that patients discharged alive from the hospital before 90 days were alive on day 90. Type of ventilator support: IMV Patients invasively ventilated from day 1 , independently of the type of support received after the eventual extubation; NIV Patients treated exclusively with noninvasive ventilation, from day 1 to study exit, independently of outcome; NIV failure Patients initially treated with noninvasive ventilation and subsequently intubated during the study period. Note: The number of patients reported in the bottom of the figure is referred to as the end of the corresponding day. (PDF $396 \mathrm{~kb}$ )

Additional file 9: Table S5. Factors associated with hospital mortality in immunocompromised patients. Multivariate logistic regression model describing the factors associated with hospital mortality in immunocompromised patients. (PDF $49 \mathrm{~kb}$ )

Additional file 10: Table S9. The most important factors leading to death in the ICU in immunocompetent and immunocompromised patients. (PDF $44 \mathrm{~kb}$ )

Additional file 11: Table S7. Patient characteristics and clinical endpoints of immunocompetent patients, according to the type of ventilatory support. (PDF $88 \mathrm{~kb}$ )

Additional file 12: Table S8. Patients' characteristics and clinical endpoints of immunocompromised (study) patients, according to the cause of immunosuppression (known, unknown). (PDF $79 \mathrm{~kb}$ )

\section{Acknowledgements}

LUNG SAFE investigators and ESICM Trial Group email address: lung-safe@esicm.org Study coordination: Guy M. Francois (European Society of Intensive Care Medicine, Brussels, Belgium).

Data revision and management: Francesca Rabboni (University of Milan-Bicocca, Monza, Italy), Fabiana Madotto (University of Milan-Bicocca, Monza, Italy), Sara Conti (University of Milan-Bicocca, Monza, Italy). LUNG SAFE executive and steering committees: John G. Laffey, Giacomo Bellani, Tai Pham, Eddy Fan, Antonio Pesenti, Laurent Brochard, Andres Esteban, Luciano Gattinoni, Frank van Haren, Anders Larsson, Daniel F. McAuley, Marco Ranieri, Gordon Rubenfeld, B. Taylor Thompson, Hermann Wrigge, Arthur S. Slutsky. National coordinators: Argentina: Fernando Rios Australia/New Zealand: Frank Van Haren 
Belgium: T. Sottiaux, P. Depuydt

Bolivia: Fredy S. Lora

Brazil: Luciano Cesar Azevedo

Canada: Eddy Fan

Chile: Guillermo Bugedo

China: Haibo Qiu

Colombia: Marcos Gonzalez

Costa Rica: Juan Silesky

Czech Republic: Vladimir Cerny

Denmark: Jonas Nielsen

Ecuador: Manuel Jibaja

France: Tài Pham

Germany: Hermann Wrigge

Greece: Dimitrios Matamis

Guatemala: Jorge Luis Ranero

India: Pravin Amin

Iran: S. M. Hashemian

Ireland: Kevin Clarkson

Italy: Giacomo Bellani

Japan: Kiyoyasu Kurahashi

Mexico: Asisclo Villagomez

Morocco: Amine Ali Zeggwagh

The Netherlands: Leo M. Heunks

Norway: Jon Henrik Laake

The Philippines: Jose Emmanuel Palo

Portugal: Antero do Vale Fernandes

Romania: Dorel Sandesc

Saudi Arabia: Yaasen Arabi

Serbia: Vesna Bumbasierevic

Spain: Nicolas Nin, Jose A. Lorente

Sweden: Anders Larsson

Switzerland: Lise Piquilloud

Tunisia: Fekri Abroug

United Kingdom: Daniel F. McAuley, Lia McNamee

Uruquay: Javier Hurtado

United States: Ed Bajwa

Venezuela: Gabriel Démpair

Site investigators by country:

Albania: University Medical Center of Tirana "Mother Theresa" (Tirana): Hektor

Sula, Lordian Nunci; University Hospital Shefqet Ndroqi (Tirana): Alma Cani

Argentina: Clinica De Especialidades (Villa Maria): Alan Zazu; Hospital Dr. Julio

C. Perrando (Resistencia): Christian Dellera, Carolina S. Insaurralde; Sanatorio

Las Lomas (San Isidro, Buenos Aires): Risso V. Alejandro; Sanatorio De La

Trinidad San Isidro (San Isidro): Julio Daldin, Mauricio Vinzio; Hospital Español

De Mendoza (Godoy Cruz-Mendoza): Ruben O. Fernandez; Hospital Del

Centenario (Rosario): Luis P. Cardonnet, Lisandro R. Bettini; San Antonio

(Gualeguay [Entre Rios]): Mariano Carboni Bisso, Emilio M. Osman; Cemic

(Buenos Aires): Mariano G. Setten, Pablo Lovazzano; Hospital Universitrario

Austral (Pilar): Javier Alvarez, Veronica Villar; Hospital Por + Salud (Pami)

Dr. Cesar Milstein (Buenos Aires): Norberto C. Pozo, Nicolas Grubissich;

Sanatorio Anchorena (Buenos Aires): Gustavo A. Plotnikow, Daniela N. Vasquez;

Sanatorio De La Trinidad Mitre (Buenos Aires): Santiago llutovich, Norberto

Tiribelli; Hospital Luis Lagomaggiore (Mendoza): Ariel Chena, Carlos A Pellegrini;

H.I.G.A. San Martín (La Plata): María G. Saenz, Elisa Estenssoro; Hospital

Misericordia (Cordoba): Matias Brizuela, Hernan Gianinetto; Sanatorio Juncal

(Temperley): Pablo E. Gomez, Valeria I. Cerrato; Hospital D. F. Santojanni

(Buenos Aires): Marco G. Bezzi, Silvina A. Borello; Hospital Alejandro Posadas

(Buenos Aires): Flavia A. Loiacono, Adriana M. Fernandez

Australia: St. Vincent's Hospital, Sydney (Darlinghurst): Serena Knowles, Claire

Reynolds; St. George Public Hospital (Kogarah): Deborah M. Inskip, Jennene J.

Miller; Westmead Hospital (Westmead): Jing Kong, Christina Whitehead;

Flinders Medical Centre (Bedford Park, South Australia): Shailesh Bihari; John

Hunter Hospital (Newcastle): Aylin Seven, Amanda Krstevski; Canberra Hospital

(Garran): Helen J. Rodgers, Rebecca T. Millar; Calvary Mater Newcastle (Waratah):

Toni E. Mckenna, Irene M. Bailey; Cabrini Hospital (Melbourne): Gabrielle C.

Hanlon; Liverpool Hospital (Liverpool): Anders Aneman, Joan M. Lynch; Coffs

Harbour Health Campus (Coffs Harbour): Raman Azad, John Neal; Sir Charles

Gairdner Hospital (Nedlands): Paul W. Woods, Brigit L. Roberts; Concord Hospital

(Concord): Mark R. Kol, Helen S. Wong

Austria: General Hospital of Vienna/Medical University of Vienna (Vienna):

Katharina C. Riss, Thomas Staudinger
Belgium: Cliniques universitaires St-Luc, Université Catholique de Louvain (UCL) (Brussels): Xavier Wittebole, Caroline Berghe; CHU Dinant-Godinne (Yvoir): Pierre A. Bulpa, Alain M. Dive; AZ Sint-Augustinus Veurne (Veurne): Rik Verstraete, Herve Lebbinck; Ghent University Hospital (Ghent): Pieter Depuydt, Joris Vermassen; University Hospitals Leuven (Leuven): Philippe Meersseman, Helga Ceunen

Brazil: Hospital Renascentista (Pouso Alegre): Jonas I. Rosa, Daniel O. Beraldo; Vitoria Apart Hospital (Serra): Claudio Piras, Adenilton M. Rampinelli; Hospital Das Clinicas (São Paulo): Antonio P. Nassar Jr.; Hospital Geral do Grajaù (São Paulo): Sergio Mataloun, Marcelo Moock; Evangelical Hospital (Cachoeiro De Itapemirim/Espírito Santo): Marlus M. Thompson, Claudio H. Gonçalves; Hospital Moinhos De Vento (Porto Alegre): Ana Carolina P. Antônio, Aline Ascoli; Hospital Alvorada Taguatinga (Taguatinga): Rodrigo S. Biondi, Danielle C. Fontenele; Complexo Hospitalar Mngabeira Tarcisio Burity (Joao Pessoa): Danielle Nobrega, Vanessa M. Sales

Brunei Darussalam: Raja Isteri Pengiran Anak Saleha (Ripas) Hospital (Bandar Seri Begawan): Dr. Suresh Shindhe, Dr. Dayangku Hajah Maizatul Aiman binti Pengiran Haji Ismail

Canada: Medical-Surgical ICU of St. Michael's Hospital (Toronto): John Laffey, Francois Beloncle; St. Joseph's Health Centre (Toronto): Kyle G. Davies, Rob Cirone; Sunnybrook Health Sciences Center (Toronto): Venika Manoharan, Mehvish Ismail; Toronto Western Hospital (Toronto): Ewan C. Goligher, Mandeep Jassal; Medical Surgical ICU of the Toronto General Hospital (Toronto): Erin Nishikawa, Areej Javeed; Cardiovascular ICU of St. Michael's Hospital (Toronto): Gerard Curley, Nuttapol Rittayamai; Cardiovascular ICU of the Toronto General Hospital (Toronto): Matteo Parotto, Niall D. Ferguson; Mount Sinai Hospital (Toronto): Sangeeta Mehta, Jenny Knoll; Trauma-Neuro ICU of St. Michael's Hospital (Toronto): Antoine Pronovost, Sergio Canestrini Chile: Hospital Clínico Pontificia Universidad Católica De Chile (Santiago): Alejandro R. Bruhn, Patricio H. Garcia; Hospital Militar De Santiago (Santiago): Felipe A. Aliaga, Pamela A. Farías; Clinica Davila (Santiago): Jacob S. Yumha; Hospital Guillermo Grant Benavente (Concepcion): Claudia A. Ortiz, Javier E. Salas; Clinica Las Lilas (Santiago): Alejandro A. Saez, Luis D. Vega; Hospital Naval Almirante Nef (Viña Del Mar): Eduardo F. Labarca, Felipe T. Martinez; Hospital Luis Tisné Brousse (Penanolen): Nicolás G. Carreño, Pilar Lora China: The Second Affiliated Hospital of Harbin Medical University (Harbin): Haitao Liu; Nanjing Zhong-Da Hospital, Southeast University (Nanjing): Haibo Qiu, Ling Liu; The First Affiliated Hospital of Anhui Medical University (Hefei): Rui/Tang, Xiaoming Luo; Peking University People's Hospital (Beijing): Youzhong An, Huiying Zhao; Fourth Affiliated Hospital of Harbin Medical University (Harbin): Yan Gao, Zhe Zhai; Nanjing Jiangbei People's Hospital Affiliated to Medical School of Southeast University (Nanjing): Zheng L. Ye, Wei Wang; The First Affiliated Hospital of Dalian Medical Unvercity (Dalian): Wenwen Li, Qingdong Li; Subei People's Hospital of Jiangsu Province (Yanghzou): Ruiqiang Zheng; Jinling Hospital (Nanjing): Wenkui Yu, Juanhong Shen; Urumqi General Hospital (Urumqi): Xinyu Li; Intensive Care Unit, First Affiliated Hospital of Wannan Medical College, Yijishan Hospital (Wuhu): Tao Yu, Weihua Lu; Sichuan Provincial People's Hospital (Chengdu): Ya Q. Wu, Xiao B. Huang; Hainan Province People's Hospital (Haikou): Zhenyang He; People's Hospital of Jiangxi Province (Nanchang): Yuanhua Lu; Qilu Hospital of Shandong University (Jinan): Hui Han, Fan Zhang; Zhejiang Provincial People's Hospital (Hangzhou): Renhua Sun; The First Affiliated Hospital of Bengbu Medical College (Bengbu, Anhui): Hua X. Wang, Shu H. Qin; Nanjing Municipal Government Hospital (Nanjing): Bao H. Zhu, Jun Zhao; The First Hospital of Lanzhou University (Lanzhou): Jian Liu, Bin Li; The First Affiliated Hospital of Chongqing University of Medical Science (Chongqing): Jing L. Liu, Fa C. Zhou; Xuzhou Central Hospital, Jiangsu Province, China (Xuzhou): Qiong J. Li, Xing Y. Zhang; The First People's Hospital of Foshan (Foshan): Zhou Li-Xin, Qiang Xin-Hua; The First Affiliated Hospital of Guangxi Medical University (Nanning): Liangyan Jiang; Renji Hospital, Shanghai Jiao Tong University School of Medicine (Shanghai): Yuan N. Gao, Xian Y. Zhao; First Hospital of Shanxi Medical University (Taiyuan): Yuan Y. Li, Xiao L. Li; Shandong Provincial Hospital (Jinan): Chunting Wang, Qingchun Yao; Fujian Provincial Hospital (Fuzhou): Rongguo Yu, Kai Chen; Henan Provincial People's Hospital (Zhengzhou): Huanzhang Shao, Bingyu Qin; The Second Affiliated Hospital of Kunming Medical University (Kunming City): Qing Q. Huang, Wei H. Zhu; Xiangya Hospital, Central South University (Changsha): Ai Y. Hang, Ma X. Hua; The First Affiliated Hospital of Guangzhou Medical University (Guangzhou): Yimin Li, Yonghao Xu; People's Hospital of Hebei Province (Shijiazhuang): Yu D. Di, Long L. Ling; Guangdong General Hospital (Guangzhou): Tie H. Qin, Shou H. Wang; Beijing Tongren Hospital (Beijing): Junping Qin; Jiangsu Province Hospital (Nanjing): Yi Han, Suming Zhou 
Colombia: Fundación Valle Del Lili (Cali): Monica P. Vargas Costa Rica: Hospital San Juan De Dios (San José): Juan I. Silesky Jimenez, Manuel A. González Rojas, Jaime E. Solis-Quesada, Christian M. Ramirez-Alfaro Czech Republic: University Hospital of Ostrava (Ostrava): Jan Máca, Peter Sklienka

Denmark: Aarhus Universitetshospital (Aarhus N): Jakob Gjedsted, Aage Christiansen; Rigshopitalet: Jonas Nielsen

Ecuador: Hospital Militar (Quito): Boris G. Villamagua, Miguel Llano

France: Clinique du Millenaire (Montpellier): Philippe Burtin, Gautier Buzancais; Centre Hospitalier (Roanne): Pascal Beuret, Nicolas Pelletier; CHU d'Angers (Angers): Satar Mortaza, Alain Mercat; Hôpital Marc Jacquet (Melun): Jonathan Chelly, Sébastien Jochmans; CHU Caen (Caen): Nicolas Terzi, Cédric Daubin; Henri Mondor Hospital (Créteil): Guillaume Carteaux, Nicolas de Prost; Cochin Hospital (Paris): Jean-Daniel Chiche, Fabrice Daviaud; Hôpital Tenon (Paris): Tai Pham, Muriel Fartoukh; CH Mulhouse-Emile Muller (Mulhouse): Guillaume Barberet, Jerome Biehler; Archet 1 University Hospital (Nice): Jean Dellamonica, Denis Doyen; Hopital Sainte Musse (Toulon): Jean-Michel Arnal, Anais Briquet; Hopital Nord - Réanimation des Détresses Respiratoires et Infections Sévères (Marseille): Sami Hraiech, Laurent Papazian; HEGP (Paris): Arnaud Follin; Louis Mourier Hospital (Colombes): Damien Roux, Jonathan Messika; Centre Hospitalier de Dax (Dax): Evangelos Kalaitzis; Réanimation Médicale, GH Pitié- Salpêtrière (Paris): Laurence Dangers, Alain Combes; AP-HP Ambroise Paré (Boulogne- Billancourt): Siu-Ming Au; University Hospital Rouen (Rouen): Gaetan Béduneau, Dorothée Carpentier; CHU Amiens (Amiens-Salouel): Elie H. Zogheib, Herve Dupont; Centre Hospitalier Intercommunal Robert Ballanger (Aulnay Sous Bois): Sylvie Ricome, Francesco L. Santoli; Centre Hospitalier René Dubos (Pontoise): Sebastien L. Besset; CHI Portes de l'Oise (Beaumont Sur Oise): Philippe Michel, Bruno Gelée; Archet 2 University Hospital (Nice): Pierre-Eric Danin, Bernard Goubaux; Centre Hospitalier Pierre Oudot (Bourgoin Jallieu): Philippe J. Crova, Nga T. Phan; $\mathrm{CH}$ Dunkerque (Dunkerque): Frantz Berkelmans; Centre Hospitalier de Belfort Montbéliard (Belfort): Julio C. Badie, Romain Tapponnier; Centre Hospitalier Emile Muller (Mulhouse): Josette Gally, Samy Khebbeb; Hôpital de Hautepierre-Hôpitaux Universitaires de Strasbourg (Strasbourg): Jean-Etienne Herbrecht, Francis Schneider; Centre Hospitalier de Dieppe (Dieppe): Pierre-Louis M Declercq, Jean-Philippe Rigaud; Bicetre (Le Kremin-Bicetre): Jacques Duranteau, Anatole Harrois; CHU Gabriel Montpied (Clermont-Ferrand): Russell Chabanne, Julien Marin; CHU Estaing (Clermont-Ferrand): Charlene Bigot, Sandrine Thibault; CHI Eure-Seine Evreux (Evreux): Mohammed Ghazi, Messabi Boukhazna; Centre Hospitalier d Châlons en Champagne (Châlons en Champagne): Salem Ould Zein; CH Beauvais (Beauvais): Jack R. Richecoeur, Daniele M. Combaux; Centre Hospitalier Le Mans (Le Mans): Fabien Grelon, Charlene Le Moal; Hôpital Fleyriat (Bourg en Bresse): Elise P. Sauvadet, Adrien Robine; Hôpital Saint Louis (Paris): Virginie Lemiale, Danielle Reuter; Service de Pneumologie Pitié-Salpétrière (Paris): Martin Dres, Alexandre Demoule; Centre Hospitalier Gonesse (Gonesse): Dany Goldgran-Toledano; Hôpital Croix Rousse (Lyon): Loredana Baboi, Claude Guérin

Germany: St. Nikolaus-Stiftshospital (Andernach): Ralph Lohner; Fachkrankenhaus Coswig GmbH (Coswig): Jens Kraßler, Susanne Schäfer; University Hospital Frankfurt (Frankfurt am Main): Kai D. Zacharowski, Patrick Meybohm; Department of Anaesthesia \& Intensive Care Medicine, University Hospital of Leipzig (Leipzig): Andreas W. Reske, Philipp Simon; Asklepios Klinik Langen (Langen): Hans-Bernd F Hopf, Michael Schuetz; Städtisches Krankenhaus Heinsberg (Heinsberg): Thomas Baltus

Greece: Hippokrateion General Hospital of Athens (Athens): Metaxia N Papanikolaou, Theonymfi G. Papavasilopoulou; University General Hospital of Thessaloniki AHEPA (Thessaloniki): Giannis A. Zacharas, Vasilis Ourailogloy; Hippokration General Hospital of Thessaloniki (Thessaloniki): Eleni K. Mouloudi, Eleni V. Massa; Hospital General of Kavala (Kavala): Eva O. Nagy, Electra E. Stamou; Papageorgiou General Hospital (Thessaloniki): Ellada V. Kiourtzieva, Marina A. Oikonomou

Guatemala: Hospital General De Enfermedades, Instituto Guatemalteco De Seguridad Social (Ciudad De Guatemala): Luis E. Avila; Centro Médico Militar (Guatemala): Cesar A. Cortez, Johanna E. Citalán India: Deenanath Mangeshkar Hospital and Research Center (Pune): Sameer A. Jog, Safal D. Sable; Care Institute of Medical Sciences (CIMS) Hospital (Ahmedabad): Bhagyesh Shah; Sanjay Gandhi Postgraduate Institute of Medical Sciences (SGPGIMS) (Lucknow): Mohan Gurjar, Arvind K. Baronia; Rajasthan Hospital (Ahmedabad): Mohammedfaruk Memon; National Institute of Mental Health and Neuro Sciences (NIMHANS) (Bangalore): Radhakrishnan Muthuchellappan, Venkatapura J. Ramesh; Anaesthesiology Unit of the
Kasturba Medical College \& Department of Respiratory Therapy, SHOAS, Manipal University (Manipal): Anitha Shenoy, Ramesh Unnikrishnan; Sanjeevan Hospital (Pune): Subhal B. Dixit, Rachana V. Rhayakar; Apollo Hospitals (Chennai): Nagarajan Ramakrishnan, Vallish K. Bhardwaj; Medicine Unit of the Kasturba Medical College and Department of Respiratory Therapy, SHOAS, Manipal University (Manipal): Heera L. Mahto, Sudha V. Sagar; G. Kuppuswamy Naidu Memorial Hospital (Coimbatore): Vijayanand Palaniswamy, Deeban Ganesan

Iran: NRITLD/Masih Daneshvari (Tehran): Seyed Mohammadreza Hashemian, Hamidreza Jamaati; Milad Hospital (Tehran): Farshad Heidari Ireland: St. Vincent's University Hospital (Dublin): Edel A. Meaney, Alistair Nichol; Mercy University Hospital (Cork): Karl M. Knapman, Donall O'Croinin; Cork University Hospital (Cork): Eimhin S. Dunne, Dorothy M. Breen; Galway University Hospital (Galway): Kevin P. Clarkson, Rola F. Jaafar; Beaumont Hospital (Dublin): Rory Dwyer, Fahd Amir; Mater Misericordiae University Hospital (Dublin): Olaitan O. Ajetunmobi, Aogan C. O'Muircheartaigh; Tallaght Hospital (Dublin): Colin S. Black, Nuala Treanor; St. James's Hospital (Dublin): Daniel V. Collins, Wahid Altaf

Italy: Santa Maria delle Croci Hospital (Ravenna): Gianluca Zani, Maurizio Fusari; Arcispedale Sant'Anna Ferrara (Ferrara): Savino Spadaro, Carlo A. Volta; Ospedale Profili (Fabriano [An]): Romano Graziani, Barbara Brunettini; Umberto I Nocera Inferiore (Nocera Inferiore Salerno): Salvatore Palmese; Azienda Ospedaliera San Paolo - Polo Universitario, Università degli Studi di Milano (Milan): Paolo Formenti, Michele Umbrello; Sant'Anna (San Fermo Della Battaglia [Co]): Andrea Lombardo; Spedali Civili Brescia (Brescia): Elisabetta Pecci, Marco Botteri; Fondazione IRCCS Ca' Granda, Ospedale Maggiore Policlinico (Milan): Monica Savioli, Alessandro Protti; University Campus Bio-Medico of Rome (Rome): Alessia Mattei, Lorenzo Schiavoni; Azienda Ospedaliera "Mellino Mellini" (Chiari [Bs]): Andrea Tinnirello, Manuel Todeschini; Policlinico P. Giaccone, University of Palermo (Palermo): Antonino Giarratano, Andrea Cortegiani; Niguarda Cà Granda Hospital (Milan): Sara Sher, Anna Rossi; A.Gemelli University Hospital (Rome): Massimo M. Antonelli, Luca M. Montini; Ospedale "Sandro Pertini" (Rome): Paolo Casalena, Sergio Scafetti; ISMeTT IRCCS UPMC (Palermo): Giovanna Panarello, Giovanna Occhipinti; Ospedale San Gerardo (Monza): Nicolò Patroniti, Matteo Pozzi; Santa Maria Della Scaletta (Imola): Roberto R. Biscione, Michela M. Poli; Humanitas Research Hospital (Rozzano): Ferdinando Raimondi, Daniela Albiero; Ospedale Desio Azienda Ospedaliera Desio-Vimercate (Desio): Giulia Crapelli, Eduardo Beck; Pinetagrande Private Hospital (Castelvolturno): Vincenzo Pota, Vincenzo Schiavone; IRCCS Azienda Ospedaliera Universitaria San Martino - IST (Genova): Alexandre Molin, Fabio Tarantino; Ospedale San Raffaele (Milano): Giacomo Monti, Elena Frati; Ospedali Riuniti Di Foggia (Foggia): Lucia Mirabella, Gilda Cinnella; Azienda Ospedaliera Luigi Sacco - Polo Universitario (Milano): Tommaso Fossali, Riccardo Colombo; A.O.U. Città della Salute e della Scienza di Torino (Turin): Pierpaolo Terragni Ilaria Pattarino; Università degli Studi di Pavia - Fondazione IRCCS Policlinico San Matteo (Pavia): Francesco Mojoli, Antonio Braschi; Azienda Ospedaliera Ospedale Civile Legnano (Legnano): Erika E. Borotto; Arnas Ospedale Civico Di Cristina Benfratelli (Palermo): Andrea N. Cracchiolo, Daniela M. Palma; Azienda Ospedaliera Della Provincia Di Lecco - Ospedale "A. Manzoni" (Lecco): Francesco Raponi, Giuseppe Foti; A.O. Provincia Di Lecco - Ospedale Alessandro Manzoni (Lecco): Ettore R. Vascotto, Andrea Coppadoro; Cliniche Universitarie Sassari (Sassari): Luca Brazzi, Leda Floris; IRCCS Policlinico San Matteo (Pavia): Giorgio A. Iotti, Aaron Venti Japan: Yokohama City University Hospital (Yokohama): Osamu Yamaguchi, Shunsuke Takagi; Toyooka Hospital (Toyooka City, Hyogo Prefecture): Hiroki N. Maeyama; Chiba University Hospital (Chiba City): Eizo Watanabe, Yoshihiro Yamaji; Okayma University Hospital (Okayama): Kazuyoshi Shimizu, Kyoko Shiozaki; Japanese Foundation for Cancer Research, Cancer Institute Hospital, Department of Emergency Medicine and Critical Care (Tokyo): Satoru Futami; Ibaraki Prefectural Central Hospital (Kasama): Sekine Ryosuke; Tohoku University Hospital (Sendai-Shi): Koji Saito, Yoshinobu Kameyama; Tokyo Medical University Hachioji Medical Center (Hachioji, Tokyo): Keiko Ueno; Tokushima University Hospital (Tokushima): Masayo Izawa, Nao Okuda; Maebashi Red Cross Hospital (Gunma Maebashi): Hiroyuki Suzuki, Tomofumi Harasawa; Urasoe General Hospital (Urasoe): Michitaka Nasu, Tadaaki Takada; Ohta General Hospital Foundation Ohta Nishinouchi Hospital (Fukushima): Fumihito Ito; Jichi Medical University Hospital (Shimotsuke): Shin Nunomiya, Kansuke Koyama; Mito Kyodo General Hospital, Tsukuba University Hospital Mito Medical Center (Mito): Toshikazu Abe; Sendai City Hospital (Sendai): Kohkichi Andoh, Kohei Kusumoto; Ja Hiroshima General Hospital (Hatsukaichi City, Hiroshima): Akira Hirata, Akihiro Takaba; Yokohama Rosai Hospital 
(Yokohama): Hiroyasu Kimura; Nagasaki University Hospital (Nagasaki): Shuhei Matsumoto, Ushio Higashijima; Niigata University Medical \& Dental Hospital (Niigata): Hiroyuki Honda, Nobumasa Aoki; Mie University Hospital (Tsu, Mie): Hiroshi Imai; Yamaguchi University Hospital (Ube, Yamaguchi): Yasuaki Ogino, Ichiko Mizuguchi; Saiseikai Kumamoto Hospital (Kumamoto City): Kazuya Ichikado; Shinshu University School of Medecine (Matsumoto City): Kenichi Nitta, Katsunori Mochizuki; Kuki General Hospital (Kuki): Tomoaki Hashida; Kyoto Medical Center (Kyoto): Hiroyuki Tanaka; Fujita Health University (Toyoake): Tomoyuki Nakamura, Daisuke Niimi; Rakwakai Marutamachi Hospital (Kyoto): Takeshi Ueda; Osaka University Hospital (Suita City, Osaka Prefecture): Yozo Kashiwa, Akinori Uchiyama

Latvia: Paul Stradins Clinical University Hospital (Riga): Olegs Sabelnikovs, Peteris Oss Lebanon: Kortbawi Hospital (Jounieh): Youssef Haddad

Malaysia: Hospital Kapit (Kapit): Kong Y. Liew

Mexico: Instituto Nacional De Cancerología, México (Mexico City): Silvio A. Ñamendys-Silva, Yves D. Jarquin-Badiola; Hospital De Especialidades "Antonio Fraga Mouret" Centro Medico Nacional La Raza IMSS (Mexico City): Luis A. Sanchez-Hurtado, Saira S. Gomez-Flores; Hospital Regional $1^{\circ}$ De Octubre (Mexico City): Maria C. Marin, Asisclo J. Villagomez; Hospital General Dr. Manuel Gea Gonzalez (Mexico City): Jordana S. Lemus, Jonathan M. Fierro; Hospital General De Zona No. 1 Instituto Mexicano Del Seguro Social Tepic Nayarit (Tepic): Mavy Ramirez Cervantes, Francisco Javier Flores Mejia; Centro Medico Dalinde (Mexico D.F.): Dulce Dector, Dulce M. Dector; OPD Hospital Civil De Guadalajara Hospital Juan I. Menchaca (Guadalajara): Daniel R. Gonzalez, Claudia R. Estrella; Hospital Regional De Ciudad Madero Pemex (Ciudad Madero): Jorge R. Sanchez- Medina, Alvaro Ramirez-Gutierrez; Centro Médico ABC (Mexico D.F.): Fernando G. George, Janet S. Aguirre; Hospital Juarez De Mexico (Mexico City): Juan A. Buensuseso, Manuel Poblano

Morocco: Mohammed V University, University Teaching Ibn Sina Hospital (Rabat): Tarek Dendane, Amine Ali Zeggwagh; Hopital Militaire D'Instruction Mohammed V (Rabat): Hicham Balkhi; Errazi (Marrakech): Mina Elkhayari, Nacer Samkaoui; University Teaching Hospital Ibn Rushd (Casablanca): Hanane Ezzouine, Abdellatif Benslama; Hôpital des Spécialités de Rabat (HSR) (Rabat): Mourad Amor, Wajdi Maazouzi

The Netherlands: Tjongerschans (Heerenveen): Nedim Cimic, Oliver Beck; CWZ (Nijmegen): Monique M. Bruns, Jeroen A. Schouten; Rijnstate Hospital (Arnhem): Myra - Rinia, Monique Raaijmakers; Radboud UMC (Nijmegen): Leo M. Heunks, Hellen M. Van Wezel; Maastricht University Medical Centre (Maastricht): Serge J. Heines, Ulrich Strauch; Catharinaziekenhuis (Eindhoven): Marc P. Buise; Academic Medical Center (Amsterdam): Fabienne D. Simonis, Marcus J. Schultz

New Zealand: Tauranga Hospital (Tauranga): Jennifer C. Goodson, Troy S. Browne; Wellington Hospital (Wellington): Leanlove Navarra, Anna Hunt; Dunedin Hospital (Dunedin): Robyn A. Hutchison, Mathew B. Bailey; Auckland City Hospital (Auckland): Lynette Newby, Colin Mcarthur; Whangarei Base Hospital (Whangarei): Michael Kalkoff, Alex Mcleod; North Shore Hospital (Auckland): Jonathan Casement, Danielle J. Hacking

Norway: Ålesund Hospital (Ålesund): Finn H. Andersen, Merete S. Dolva; Oslo University Hospital Rikshospitalet Medical Centre (Oslo): Jon H. Laake, Andreas Barratt-Due; Stavanger University Hospital (Stavanger): Kim Andre L. Noremark, Eldar Søreide; Haukeland University Hospital (Bergen): Brit Å. Sjøbø, Anne B. Guttormsen

Peru: Hospital Nacional Edgardo Rebagliati Martins (Lima): Hector H. Leon Yoshido; Clínica Ricardo Palma (Lima): Ronald Zumaran Aguilar, Fredy A. Montes Oscanoa

The Philippines: The Medical City (Pasig): Alain U. Alisasis, Joanne B. Robles; Chong Hua Hospital (Cebu): Rossini Abbie B. Pasanting-Lim, Beatriz C. Tan Poland: Warsaw University Hospital (Warsaw): Pawel Andruszkiewicz, Karina Jakubowska

Portugal: Centro Hospitalar da Cova da Beira (Covilhã): Cristina M. Coxo; Hospital Santa Maria, Centro Hospitalar Lisboa Norte (Lisboa): António M. Alvarez, Bruno S. Oliveira; Centro Hospitalar Trás-os-Montes e Alto Douro - Hospital de S. Pedro - Vila Real (Vila Real): Gustavo M. Montanha, Nelson C. Barros; Hospital Beatriz Ângelo (Loures): Carlos S. Pereira, António M. Messias; Hospital de Santa Maria (Lisboa): Jorge M. Monteiro; Centro Hospitalar Médio Tejo - Hospital De Abrantes (Abrantes): Ana M. Araujo, Nuno T. Catorze; Instituto Português de Oncologia de Lisboa (Lisboa): Susan M. Marum, Maria J. Bouw; Hospital Garcia De Orta (Almada): Rui M. Gomes, Vania A. Brito; Centro Hospitalar do Algarve (Faro): Silvia Castro, Joana M. Estilita; HPP Hospital De Cascais (Alcabideche): Filipa M. Barros; Hospital Prof. Doutor Fernando Fonseca Epe (Amadora): Isabel M. Serra, Aurelia.
Romania: Fundeni Clinical Institute (Bucharest): Dana R. Tomescu, Alexandra Marcu; Emergency Clinical County Hospital Timisoara (Timisoara): Ovidiu H. Bedreag, Marius Papurica; Elias University Emergency Hospital (Bucharest): Dan E. Corneci, Silvius loan Negoita

Russian Federation: University Hospital (Kemerovo): Evgeny Grigoriev; Krasnoyarsk Regional Hospital, Krasnoyarsk State Medical University (Krasnoyarsk): Alexey I. Gritsan, Andrey A. Gazenkampf Saudi Arabia: GICU of PSMMC (Riyadh): Ghaleb Almekhlafi, Mohamad M. Albarrak; SICU of PSMMC (Riyadh): Ghanem M. Mustafa; King Faisal Hospital and Research Center (Riyadh): Khalid A. Maghrabi, Nawal Salahuddin; King Fahad Hospital (Baha): Tharwat M. Aisa; King Abdulaziz Medical City (Riyadh): Ahmed S. Al Jabbary, Edgardo Tabhan; King Abdulaziz Medical City (Riyadh): Yaseen M. Arabi; King Abdulaziz Medical City (Riyadh): Yaseen M. Arabi, Olivia A. Trinidad; King Abdulaziz Medical City (Riyadh): Hasan M. Al Dorzi, Edgardo E. Tabhan

South Africa: Charlotte Maxeke Johannesburg Academic Hospital (Johannesburg): Stefan Bolon, Oliver Smith

Spain: Hospital Sant Pau (Barcelona): Jordi Mancebo, Hernan Aguirre-Bermeo; Hospital Universitari Bellvitge (L'Hospitalet de Llobregat (Barcelona)): Juan C. Lopez-Delgado, Francisco Esteve; Hospital Son Llatzer (Palma de Mallorca): Gemma Rialp, Catalina Forteza; Sabadell Hospital, CIBER Enfermedades Respiratorias (Sabadell): Candelaria de Haro, Antonio Artigas; Hospital Universitario Central de Asturias (Oviedo): Guillermo M. Albaiceta, Sara de Cima- Iglesias; Complejo Hospitalario Universitario de A Coruña (A Coruña): Leticia Seoane-Quiroga, Alexandra Ceniceros-Barros; Hospital Universitario Miguel Servet (Zaragoza): Antonio L. Ruiz- Aguilar, Luis M. Claraco-Vega; Morales Meseguer University Hospital (Murcia): Juan Alfonso Soler, Maria del Carmen Lorente; Hospital Universitario del Henares (Coslada): Cecilia Hermosa, Federico Gordo; Complejo Asistencial de Palencia. Hospital Rio Carrión (Palencia): Miryam Prieto-González, Juan B. López-Messa; Fundación Jiménez Díaz (Madrid): Manuel P. Perez, Cesar P. Perez; Hospital Clínico Universitario Lozano Blesa (Zaragoza): Raquel Montoiro Allue; Hospital Verge de la Cinta (Tortosa): Ferran Roche-Campo, Marco Ibañez-Santacruz; Hospital Universitario 12 de Octubre (Madrid): Susana Temprano; Hospital Universitario Príncipe de Asturias (Alcalá de Henares, Madrid): Maria C. Pintado, Raul de Pablo; Hospital Universitari Germans Trias i Pujol (Badalona): Pilar Ricart Aroa Gómez; Hospital Universitario Arnau de Vilanova de Lleida (Lleida): Silvia Rodriguez Ruiz, Silvia Iglesias Moles; Consorci Sanitari de Terrassa - Hospital de Terrassa (Barcelona): Maria Teresa Jurado, Alfons Arizmendi; Hospital Universitari Mútua Terrassa (Terrassa): Enrique A. Piacentini; Hospital Universitario de Móstoles (Mostoles): Nieves Franco, Teresa Honrubia; Complejo Asistencial de Salamanca (Salamanca): Meisy Perez Cheng, Elena Perez Losada; Hospital General Universitario de Ciudad Real (Ciudad Real): Javier Blanco, Luis J. Yuste; Torrecardenas (Almeria): Cecilia Carbayo-Gorriz, Francisca G. Cazorla-Barranquero; Hospital Universitario Donostia (San Sebastian): Javier G. Alonso, Rosa S. Alda; Hospital Universitario de Torrejón (Madrid): Ángela Algaba, Gonzalo Navarro; Hospital Universitario de La Princesa (Madrid): Enrique Cereijo, Esther Diaz-Rodriguez; Hospital Universitario Lucus Augusti (Lugo): Diego Pastor Marcos, Laura Alvarez Montero; Hospital Universitario Santa Lucia (Cartagena): Luis Herrera Para, Roberto Jimenez Sanchez; Hospital Universitario Severo Ochoa, Leganes (Madrid): Miguel Angel Blasco Navalpotro, Ricardo Diaz Abad; University Hospital of Nuestra Señora de Candelaria (Santa Cruz de Tenerife): Raquel Montiel González, Dácil Parrilla Toribio; Hospital Universitario Marques de Valdecilla (Santander): Alejandro G. Castro, Maria Jose D. Artiga; Hospital Infanta Cristina (Parla, Madrid): Oscar Penuelas; Hospital General de Catalunya (Sant Cugat Del Valles): Tomas P. Roser, Moreno F. Olga; San Pedro de Alcántara (Cáceres): Elena Gallego Curto, Rocío Manzano Sánchez; Sant Joan de Reus (Reus): Vallverdu P. Imma, Garcia M. Elisabet; Hospital Joan XXIII (Tarragona): Laura Claverias, Monica Magret; Hospital Universitario de Getafe (Madrid): Ana M. Pellicer, Lucia L. Rodriguez; Hospital Universitario Río Hortega (Valladolid): Jesús Sánchez-Ballesteros, Ángela González-Salamanca; Hospital Arquitecto Marcide (Ferrol, A Coruña): Antonio G. Jimenez, Francisco P. Huerta; Hospital General Universitario Gregorio Marañón (Madrid): Juan Carlos J. Sotillo Diaz, Esther Bermejo Lopez; Hospital General de Segovia (Segovia): David D. Llinares Moya, Alec A. Tallet Alfonso; Hospital General Universitario Reina Sofia (Murcia): Palazon Sanchez Eugenio Luis, Palazon Sanchez Cesar; Complejo Hospitalario Universitario de Albacete (Albacete): Sánchez I. Rafael, Corcoles G. Virgilio; Hospital Infanta Elena (Valdemoro): Noelia N. Recio Sweden: Sahlgrenska University Hospital (Gothenburg): Richard O. Adamsson, Christian C. Rylander; Karolinska University Hospital (Stockholm): Bernhard Holzgraefe, Lars M. Broman; Akademiska Sjukhuset Uppsala (Uppsala): Joanna Wessbergh, Linnea Persson; Vrinnevisjukhuset (Norrköping): Fredrik Schiöler, 
Hans Kedelv; Linkoping University Hospital (Linköping): Anna Oscarsson Tibblin, Henrik Appelberg; Skellefteå Lasarett (Skellefteå): Lars Hedlund, Johan Helleberg; Karolinska University Hospital Solna (Stockholm): Karin E. Eriksson, Rita Glietsch; Umeå University Hospital (Umeå): Niklas Larsson, Ingela Nygren; Danderyd Hospital (Stockholm): Silvia L. Nunes, Anna-Karin Morin; Lund University Hospital (Lund): Thomas Kander, Anne Adolfsson

Switzerland: CHUV (Centre hospitalier universitaire vaudois) (Lausanne): Lise Piquilloud; Hôpital neuchâtelois - La Chaux-de-Fonds (La Chaux-de-Fonds): Hervé O. Zender, Corinne Leemann-Refondini

Tunisia: Hopital Taher Sfar Mahdia (Mahdia): Souheil Elatrous; University Hospital Farhat Hached Sousse (Sousse): Slaheddine Bouchoucha, Imed Chouchene; CHU F. Bourguiba (Monastir): Islem Ouanes; Mongi Slim University Hospital, La Marsa (La Marsa): Asma Ben Souissi, Salma Kamoun Turkey: Cerrahpasa Medical Faculty Emergency Intensive Care Unit (Istanbul): Oktay Demirkiran; Cerrahpasa Medical Faculty Sadi Sun Intensive Care Unit (Istanbul): Mustafa Aker, Emre Erbabacan; Uludag University Medical Faculty (Bursa): Ilkay Ceylan, Nermin Kelebek Girgin; Ankara University Faculty of Medicine, Reanimation, Level 3 ICU (Ankara): Menekse Ozcelik, Necmettin Ünal; Ankara University Faculty of Medicine, Level 2 ICU-Postoperative ICU (Ankara): Basak Ceyda Meco; Istanbul Kartal Eğitim ve Araştırma Hastanesi (Istanbul): Onat O. Akyol, Suleyman S. Derman

United Kingdom: Papworth Hospital (Cambridge): Barry Kennedy, Ken Parhar; Royal Glamorgan Hospital (Llantrisant): Latha Srinivasa; Royal Victoria HospitalBelfast (Belfast): Lia McNamee, Danny McAuley; Jack Steinberg Critical Care Unit, King's College London (London): Phil Hopkins, Clare Mellis; Frank Stansil Critical Care Unit, King's College Hospital (London): Vivek Kakar; Liver ICU of King's College London (London): Dan Hadfield; Christine Brown Critical Care Unit, King's College London (London): Andre Vercueil; West Suffolk Hospital (Bury St. Edmunds): Kaushik Bhowmick, Sally K. Humphreys; Craigavon Area Hospital (Portadown): Andrew Ferguson, Raymond Mckee; Barts Health NHS Trust, Whipps Cross Hospital (Leytonstone): Ashok S. Raj, Danielle A. Fawkes; Kettering General Hospital, Foundation NHS Trust (Northamptonshire): Philip Watt, Linda Twohey; Barnet General Hospital (Barnet): Rajeev R. JhaMatthew Thomas, Alex Morton, Varsha Kadaba; Rotherham General Hospital (Rotherham): Mark J. Smith, Anil P. Hormis; City Hospital (Birmingham): Santhana G. Kannan, Miriam Namih; Poole Hospital NHS Foundation Trust (Poole): Henrik Reschreiter, Julie Camsooksai; Weston General Hospital (Weston-Super-Mare): Alek Kumar, Szabolcs Rugonfalvi; Antrim Area Hospital (Antrim): Christopher Nutt, Orla Oneill; Aintree University Hospital (Liverpool): Colette Seasman, Ged Dempsey; Northern General Hospital (Sheffield): Christopher J. Scott, Helen E. Ellis; John Radcliffe Hospital (Oxford): Stuart Mckechnie, Paula J. Hutton; St. George's Hospital (London): Nora N. Di Tomasso, Michela N. Vitale; Hillingdon Hospital (Uxbridge): Ruth Griffin, Michael N. Dean; The Royal Bournemouth \& Christchurch NHS Foundation Trust (Bournemouth, Dorset): Julius H. Cranshaw, Emma L. Willett; Severe Respiratory Failure Service, Guy's and St. Thomas' NHS Foundation Trust (London): Nicholas loannou; Whittington Hospital (London): Sarah Gillis; Wexham Park Hospital (Slough): Peter Csabi; Western General Hospital (Edinburgh): Rosaleen Macfadyen, Heidi Dawson; Royal Preston Hospital (Preston): Pieter D. Preez, Alexandra J. Williams; Brighton and Sussex University Hospitals NHS Trust (Brighton): Owen Boyd, Laura Ortiz-Ruiz de Gordoa; East and North Herts NHS Trust (Stevenage): Jon Bramall, Sophie Symmonds; Barnsley Hospital (Barnsley): Simon K. Chau, Tim Wenham; Prince Charles Hospital (Merthyr Tydfil): Tamas Szakmany, Piroska Toth-Tarsoly; University Hospital of South Manchester NHS Foundation Trust (Manchester): Katie H. Mccalman, Peter Alexander; Harrogate District Hospital (Harrogate): Lorraine Stephenson, Thomas Collyer; East and North Herts NHS Trust (Welwyn Garden City): Rhiannon Chapman, Raphael Cooper; Western Infirmary (Glasgow): Russell M. Allan, Malcolm Sim; Dumfries and Galloway Royal Infirmary (Dumfries): David W. Wrathall, Donald A. Irvine; Charing Cross Hospital (London): Kim S. Zantua, John C. Adams; Worcestershire Royal Hospital (Worcester): Andrew J. Burtenshaw, Gareth P. Sellors; Royal Liverpool University Hospital (Liverpool): Ingeborg D. Welters, Karen E. Williams; Royal Alexandra Hospital (Glasgow): Robert J. Hessell, Matthew G. Oldroyd; Morriston Hospital (Swansea): Ceri E. Battle, Suresh Pillai; Frimley Park Hospita (Frimley): Istvan - Kajtor, Mageswaran - Sivashanmugavel; Altnagelvin Hospital (Derry): Sinead C. Okane, Adrian Donnelly; Buckinghamshire Healthcare NHS Trust (High Wycombe, Buckinghamshire): Aniko D. Frigyik, Jon P. Careless; Milton Keynes Hospital (Milton Keynes): Martin M. May, Richard Stewart; Ulster Hospital (Belfast): T. John Trinder, Samantha J. Hagan; University Hospital of Wales (Cardiff): Matt P. Wise, Jade M. Cole; Freeman Hospital (Newcastle Upon Tyne): Caroline C. MacFie, Anna T. Dowling Uruquay: Hospital Español (Montevideo): Javier Hurtado, Nicolás Nin; Cudam (Montevideo): Javier Hurtado; Sanatorio Mautone (Maldonado): Edgardo
Nuñez; Sanatorio Americano (Montevideo): Gustavo Pittini, Ruben Rodriguez; Hospital de Clínicas (Montevideo): María C Imperio, Cristina Santos; Circulo Católico Obreros Uruguay - Sanatorio Juan Pablo II (Montevideo): Ana G. França, Alejandro Ebeid; CASMU (Montevideo): Alberto Deicas, Carolina Serra United States: St. Louis University Hospital (St. Louis, MO): Aditya Uppalapati, Ghassan Kamel; Beth Israel Deaconess Medical Center (Boston, MA): Valerie M. Banner-Goodspeed, Jeremy R. Beitler; Memorial Medical Center (Springfield, IL): Satyanarayana Reddy Mukkera, Shreedhar Kulkarni; Massachusetts General Hospital (Boston, MA): Jarone Lee, Tomaz Mesar; University of Cincinnati Medical Center (Cincinnati, $\mathrm{OH}$ ): John O Shinn lii, Dina - Gomaa; Massachusetts General Hospital (Boston, MA): Christopher Tainter, Jarone Lee; Massachusetts General Hospital (Boston, MA): Tomaz Mesar, Jarone Lee; R. Adams Cowley Shock Trauma Center, University of Maryland Medical Center (Baltimore, MD): Dale J. Yeatts, Jessica Warren; Intermountain Medical Center (Murray, UT): Michael J. Lanspa, Russel R. Miller, Colin K. Grissom, Samuel M. Brown; Mayo Clinic (Rochester, MN): Philippe R. Bauer; North Shore Medical Center (Salem, MA): Ryan J. Gosselin, Barrett T. Kitch; Albany Medical Center (Albany, NY): Jason E. Cohen, Scott H. Beegle; John H. Stoger Hospital of Cook County (Chicago, IL): Renaud M. Gueret, Aiman Tulaimat; Albany Medical Center (Albany, NY); Shazia Choudry; University of Alabama at Birmingham (UAB) (Birmingham, AL): William Stigler, Hitesh Batra; Duke University Hospital (Durham, NC): Nidhi G. Huff; lowa Methodist Medical Center (Des Moines, IA): Keith D. Lamb, Trevor W. Oetting; Surgical \& Neurosciences Intensive Care Unit of the University of lowa Hospitals and Clinics (lowa City, IA): Nicholas M. Mohr, Claine Judy; Medical Center of Louisiana at New Orleans (New Orleans, LA): Shigeki Saito, Fayez M. Kheir; Tulane University (New Orleans, LA): Fayez Kheir; Critical Care Unit of the University of lowa Hospitals and Clinics (lowa City, IA): Adam B. Schlichting, Angela Delsing; University of California, San Diego Medical Center (San Diego, CA): Daniel R. Crouch, Mary Elmasri; UC San Diego Thornton Hospital (La Jolla, CA): Daniel R. Crouch, Dina Ismail; University Hospital (Cincinnati, OH): Kyle R. Dreyer, Thomas C. Blakeman; University Hospital (Cincinnati, OH): Kyle R. Dreyer, Dina Gomaa; Tower 3B Medical ICU of Brigham and Women's Hospital (Boston, MA): Rebecca M. Baron, Carolina Quintana Grijalba; Tower 8C Burn/Trauma ICU of Brigham and Women's Hospital (Boston, MA): Peter C. Hou; Tower 8D Surgical ICU of Brigham and Women's Hospital (Boston, MA): Raghu Seethala; Tower 9C Neurosurgical ICU of Brigham and Women's Hospital (Boston, MA): Imo Aisiku; Tower 9D Neurological ICU of Brigham and Women's Hospital (Boston, MA): Galen Henderson; Tower 11C Thoracic ICU of Brigham and Women's Hospital (Boston, MA): Gyorgy Frendl; Carl J. and Ruth Shapiro Cardiovascular Center, Brigham and Women's Hospital (Boston, MA): Sen-Kuang Hou, Robert L. Owens, Ashley Schomer

Serbia: Clinical Center of Serbia (Belgrade): Vesna Bumbasirevic, Bojan Jovanovic; Military Medical Academy (Belgrade): Maja Surbatovic, Milic Veljovic

\section{Funding}

The authors received no funding for this study. However, the LUNG SAFE study was funded and supported by the European Society of Intensive Care Medicine (ESICM; Brussels, Belgium), St. Michael's Hospital (Toronto, ON, Canada), and the University of Milano-Bicocca (Monza, Italy).

\section{Availability of data and materials}

All data supporting this article are available in the text and additional files.

\section{Authors' contributions}

$G C$ and $A C$ are the guarantors of this article. $A C, C G, G B, J G L, T P, F V H, A G, M A, A P$, and GG conceived of and designed the study. AC, FM, CG, GB, JGL, TP, FVH, AG, $M A, A P$, and $G G$ analyzed and interpreted data. AC, FM, CG, and GG drafted the manuscript. All authors critically revised the manuscript for important intellectual content. All authors read and provided final approval of the final version.

\section{Ethics approval and consent to participate}

Not applicable.

\section{Competing interests}

AC, FM, JGL, TP, and FVH declare that they have no competing interests. CG received fees for consultancies or lectures from Orion Pharma, ResMed, Medtronic, Philips, Air Liquide, and EOVE (all unrelated to the present work). GB received fees for lectures from Draeger Medical, GE Healthcare, and Pfizer; research grants from Draeger Medical; and is president and a 
shareholder of ReviewerCredits S.R.L. (all unrelated to the present work). AG received fees for consultancies or lectures from Orion, Pfizer, and MSD (all unrelated to the present work). MA received research grants from Toray, GE Healthcare, and Orion and participated on the boards and received personal fees from Maquet, Pfizer, and MSD (all unrelated to the present work). AP received fees from Maquet, Novalung, Xenios, Baxter, and Boerhinger Ingelheim (all unrelated to the present work). GG received fees for lectures from Thermo Fisher Scientific and Pfizer and travel accommodation support from Maquet and Biotest (all unrelated to the present work).

\section{Publisher's Note}

Springer Nature remains neutral with regard to jurisdictional claims in published maps and institutional affiliations.

\section{Author details}

'Department of Biopathology and Medical Biotechnologies (DIBIMED), Section of Anesthesia, Analgesia, Intensive Care and Emergency, Policlinico Paolo Giaccone, University of Palermo, Via del vespro 129, 90127 Palermo, Italy. ${ }^{2}$ Research Center on Public Health, Department of Medicine and Surgery, University of Milano-Bicocca, Monza, Italy. ${ }^{3}$ School of Medicine and Surgery, University of Milano-Bicocca, Monza, Italy. ${ }^{4}$ Department of Emergency and Intensive Care, San Gerardo Hospital, Monza, Italy. ${ }^{5}$ Anesthesia, School of Medicine, National University of Ireland, Galway, Ireland. Interdepartemental Division of Critical Care Medicine, University of Toronto, Toronto, ON, Canada. ${ }^{7}$ Keenan Research Center for Biomedical Science, Li Ka Shing Knowledge Institute, St. Michael's Hospital, Toronto, Canada. ${ }^{8} \mathrm{College}$ of Medicine, Biology and Environment, Australian National University, Canberra, Australia. ${ }^{9}$ Intensive Care Unit, Canberra Hospital, Canberra, Australia. ${ }^{10}$ Department of Anesthesiology and Intensive Care, Università Cattolica del Sacro Cuore - Fondazione Policlinico Universitario A. Gemelli, Rome, Italy. ${ }^{11}$ Department of Anesthesiology, Intensive Care and Emergency, Fondazione IRCCS Ca' Granda Ospedale Maggiore Policlinico, Milan, Italy. ${ }^{12}$ Department of Pathophysiology and Transplantation, University of Milan, Milan, Italy.

\section{Received: 26 February 2018 Accepted: 22 May 2018}

Published online: 12 June 2018

\section{References}

1. Bird GT, Farquhar-Smith P, Wigmore T, Potter M, Gruber PC. Outcomes and prognostic factors in patients with haematological malignancy admitted to a specialist cancer intensive care unit: a 5 yr study. Br J Anaesth. 2012;108:452-9.

2. Kostakou E, Rovina N, Kyriakopoulou M, Koulouris NG, Koutsoukou A. Critically ill cancer patient in intensive care unit: issues that arise. J Crit Care. 2014;29:817-22.

3. Mokart D, Pastores SM, Darmon M. Has survival increased in cancer patients admitted to the ICU? Yes. Intensive Care Med. 2014;40:1570-2.

4. Azoulay E, Soares M, Benoit D. Focus on immunocompromised patients. Intensive Care Med. 2016;42:463-5.

5. Azoulay E, Mokart D, Pene F, Lambert J, Kouatchet A, Mayaux J, Vincent F, Nyunga M, Bruneel F, Laisne L-M, Rabbat A, Lebert C, Perez P, Chaize M, Renault A, Meert A-P, Benoit D, Hamidfar R, Jourdain M, Darmon M, Schlemmer B, Chevret S, Lemiale V. Outcomes of critically ill patients with hematologic malignancies: prospective multicenter data from France and Belgium-a Groupe de Recherche Respiratoire en Reanimation Onco-Hematologique Study. J Clin Oncol. 2013;31:2810-8.

6. Fisher R, Dangoisse C, Crichton S, Whiteley C, Camporota L, Beale R, Ostermann M. Short-term and medium-term survival of critically ill patients with solid tumours admitted to the intensive care unit: a retrospective analysis. BMJ Open. 2016;6:e011363

7. Normilio-Silva K, de Figueiredo AC, Pedroso-de-Lima AC, Tunes-da-Silva G, Nunes da Silva A, Delgado Dias Levites A, de-Simone AT, Lopes Safra P, Zancani R, Tonini PC, Vasconcelos de Andrade E Silva U, Buosi Silva T, Martins Giorgi J, Eluf-Neto J, Costa A, Abrahao Hajjar L, Biasi Cavalcanti A. Long-term survival, quality of life, and quality-adjusted survival in critically ill patients with cancer. Crit Care Med. 2016;44:1327-37.

8. Azevedo LCP, Caruso P, Silva UVA, Torelly AP, Silva E, Rezende E, Netto J, Piras C, Lobo SMA, Knibel MF, Teles JM, Lima RA, Ferreira BS, Friedman G, Rea-Neto A, Dal-Pizzol F, Bozza FA, Salluh JIF, Soares M. Outcomes for patients with cancer admitted to the ICU requiring ventilatory support: results from a prospective multicenter study. Chest. 2014;146:257-66.

9. Puxty K, McLoone P, Quasim T, Kinsella J, Morrison D. Survival in solid cancer patients following intensive care unit admission. Intensive Care Med. 2014;40:1409-28.

10. Pene F, Salluh JIF, Staudinger T. Has survival increased in cancer patients admitted to the ICU? No. Intensive Care Med. 2014;40:1573-5.

11. Contejean A, Lemiale V, Resche-Rigon M, Mokart D, Pene F, Kouatchet A, Mayaux J, Vincent F, Nyunga M, Bruneel F, Rabbat A, Perez P, Meert AP, Benoit D, Hamidfar R, Darmon M, Jourdain M, Renault A, Schlemmer B, Azoulay E. Increased mortality in hematological malignancy patients with acute respiratory failure from undetermined etiology: a Groupe de Recherche en Reanimation Respiratoire en Onco-Hematologique (Grrr-OH) study. Ann Intensive Care. 2016;6:102

12. Molina R, Bernal T, Borges M, Zaragoza R, Bonastre J, Granada RM, Rodriguez-Borregan JC, Nunez K, Seijas I, Ayestaran I, Albaiceta GM. Ventilatory support in critically ill hematology patients with respiratory failure. Crit Care. 2012;16:R133.

13. Huang HB, Xu B, Liu GY, Lin JD, Du B. Use of noninvasive ventilation in immunocompromised patients with acute respiratory failure: a systematic review and meta-analysis. Crit Care. 2017;21:4.

14. Gregoretti C, Pisani L, Cortegiani A, Ranieri VM. Noninvasive ventilation in critically ill patients. Crit Care Clin. 2015;31:435-57.

15. Bello G, De Pascale G, Antonelli M. Noninvasive ventilation for the immunocompromised patient: always appropriate? Curr Opin Crit Care. 2012;18:54-60.

16. Antonelli M, Conti G, Bufi M, Costa MG, Lappa A, Rocco M, Gasparetto A, Meduri GU. Noninvasive ventilation for treatment of acute respiratory failure in patients undergoing solid organ transplantation: a randomized trial. JAMA. 2000;283:235-41.

17. Hilbert G, Gruson D, Vargas F, Valentino R, Gbikpi-Benissan G, Dupon M, Reiffers J, Cardinaud JP. Noninvasive ventilation in immunosuppressed patients with pulmonary infiltrates, fever, and acute respiratory failure. N Engl J Med. 2001;344:481-7.

18. Lemiale V, Mokart D, Resche-Rigon M, Pene F, Mayaux J, Faucher E, Nyunga M, Girault C, Perez P, Guitton C, Ekpe K, Kouatchet A, Theodose I, Benoit D, Canet E, Barbier F, Rabbat A, Bruneel F, Vincent F, Klouche K, Loay K, Mariotte E, Bouadma L, Moreau A-S, Seguin A, Meert A-P, Reignier J, Papazian L, Mehzari I, Cohen $Y$, et al. Effect of noninvasive ventilation vs oxygen therapy on mortality among immunocompromised patients with acute respiratory failure: a randomized clinical trial. JAMA. 2015;314:1711-9.

19. Depuydt PO, Benoit DD, Vandewoude KH, Decruyenaere JM, Colardyn FA. Outcome in noninvasively and invasively ventilated hematologic patients with acute respiratory failure. Chest. 2004;126:1299-306.

20. Adda M, Coquet I, Darmon M, Thiery G, Schlemmer B, Azoulay E. Predictors of noninvasive ventilation failure in patients with hematologic malignancy and acute respiratory failure. Crit Care Med. 2008;36:2766-72.

21. Frat JP, Ragot S, Girault C, Perbet $S$, Prat G, Boulain T, Demoule A, Ricard JD, Coudroy R, Robert R, Mercat A, Brochard L, Thille AW. Effect of non-invasive oxygenation strategies in immunocompromised patients with severe acute respiratory failure: a post-hoc analysis of a randomised trial. Lancet Respir Med. 2016:4:646-52.

22. Cortegiani A, Russotto V, Antonelli M, Azoulay E, Carlucci A, Conti G, Demoule A, Ferrer M, Hill NS, Jaber S, Navalesi P, Pelosi P, Scala R, Gregoretti C. Ten important articles on noninvasive ventilation in critically ill patients and insights for the future: a report of expert opinions. BMC Anesthesiol. 2017;17:122.

23. Bellani G, Laffey JG, Pham T, Fan E, Brochard L, Esteban A, Gattinoni L, van Haren F, Larsson A, McAuley DF, Ranieri M, Rubenfeld G, Thompson BT, Wrigge $H$, Slutsky AS, Pesenti A. Epidemiology, patterns of care, and mortality for patients with acute respiratory distress syndrome in intensive care units in 50 countries. JAMA. 2016;315:788-800.

24. Bellani G, Laffey JG, Pham T, Madotto F, Fan E, Brochard L, Esteban A, Gattinoni L, Bumbasirevic V, Piquilloud L, van Haren F, Larsson A, McAuley DF, Bauer PR, Arabi YM, Ranieri M, Antonelli M, Rubenfeld GD, Thompson BT, Wrigge H, Slutsky AS, Pesenti A. Noninvasive ventilation of patients with acute respiratory distress syndrome: insights from the LUNG SAFE study. Am J Respir Crit Care Med. 2017;195:67-77.

25. Ranieri VM, Rubenfeld GD, Thompson BT, Ferguson ND, Caldwell E, Fan E, Camporota L, Slutsky AS. Acute respiratory distress syndrome: the Berlin Definition. JAMA. 2012;307:2526-33.

26. Gristina GR, Antonelli M, Conti G, Ciarlone A, Rogante S, Rossi C, Bertolini G. Noninvasive versus invasive ventilation for acute respiratory failure in 
patients with hematologic malignancies: a 5-year multicenter observational survey. Crit Care Med. 2011;39:2232-9.

27. Laffey JG, Bellani G, Pham T, Fan E, Madotto F, Bajwa EK, Brochard L, Clarkson K, Esteban A, Gattinoni L, van Haren F, Heunks LM, Kurahashi K, Laake JH, Larsson A, McAuley DF, McNamee L, Nin N, Qiu H, Ranieri M, Rubenfeld GD, Thompson BT, Wrigge H, Slutsky AS, Pesenti A. Potentially modifiable factors contributing to outcome from acute respiratory distress syndrome: the LUNG SAFE study. Intensive Care Med. 2016;42:1865-76.

28. Azoulay E, Lemiale V, Mokart D, Pene F, Kouatchet A, Perez P, Vincent F, Mayaux J, Benoit D, Bruneel F, Meert AP, Nyunga M, Rabbat A, Darmon M. Acute respiratory distress syndrome in patients with malignancies. Intensive Care Med. 2014;40:1106-14.

29. Benoit DD, Soares M, Azoulay E. Has survival increased in cancer patients admitted to the ICU? We are not sure. Intensive Care Med. 2014;40:1576-9.

30. Grasselli G. ICU admission of patients with hematological malignancies: the debate continues. Minerva Anestesiol. 2013;79:113-5.

31. Raoof ND, Groeger JS. You never know —one of your patients with cancer might surprise you. Crit Care Med. 2007;35:965-6.

32. Thille AW, Contou D, Fragnoli C, Cordoba-Izquierdo A, Boissier F, Brun-Buisson C. Non-invasive ventilation for acute hypoxemic respiratory failure: intubation rate and risk factors. Crit Care. 2013;17:R269.

33. Demoule A, Chevret S, Carlucci A, Kouatchet A, Jaber S, Meziani F, Schmidt M, Schnell D, Clergue C, Aboab J, Rabbat A, Eon B, Guerin C, Georges H, Zuber B, Dellamonica J, Das V, Cousson J, Perez D, Brochard L, Azoulay E. Changing use of noninvasive ventilation in critically ill patients: trends over 15 years in francophone countries. Intensive Care Med. 2016:42:82-92.

34. Patel BK, Wolfe KS, PohIman AS, Hall JB, Kress JP. Effect of noninvasive ventilation delivered by helmet vs face mask on the rate of endotracheal intubation in patients with acute respiratory distress syndrome: a randomized clinical trial. JAMA. 2016;315:2435-41.

35. Azoulay E, Schellongowski P, Darmon M, Bauer PR, Benoit D, Depuydt P, Divatia JV, Lemiale V, van Vliet M, Meert AP, Mokart D, Pastores SM, Perner A, Pene F, Pickkers P, Puxty KA, Vincent F, Salluh J, Soubani AO, Antonelli M, Staudinger T, Bergwelt-Baildon v M, Soares M. The Intensive Care Medicine research agenda on critically ill oncology and hematology patients. Intensive Care Med. 2017;43:1366-82.

\section{Ready to submit your research? Choose BMC and benefit from:}

- fast, convenient online submission

- thorough peer review by experienced researchers in your field

- rapid publication on acceptance

- support for research data, including large and complex data types

- gold Open Access which fosters wider collaboration and increased citations

- maximum visibility for your research: over $100 \mathrm{M}$ website views per year 